This item was submitted to Loughborough's Research Repository by the author.

Items in Figshare are protected by copyright, with all rights reserved, unless otherwise indicated.

\title{
Devulcanization and recycling of waste automotive EPDM rubber powder by using shearing action and chemical additive
}

\section{PLEASE CITE THE PUBLISHED VERSION}

http://www.polymerjournals.com/ProgressRubberPlastic.asp

\section{PUBLISHER}

(C) Smithers RAPRA

\section{VERSION}

AM (Accepted Manuscript)

\section{PUBLISHER STATEMENT}

This work is made available according to the conditions of the Creative Commons Attribution-NonCommercialNoDerivatives 4.0 International (CC BY-NC-ND 4.0) licence. Full details of this licence are available at: https://creativecommons.org/licenses/by-nc-nd/4.0/

\section{LICENCE}

CC BY-NC-ND 4.0

\section{REPOSITORY RECORD}

Movahed, Saeed Ostad, Ali Ansarifar, Nezhad Sakineh Karbalaee, and Sepideh Atharyfar. 2017.

"Devulcanization and Recycling of Waste Automotive EPDM Rubber Powder by Using Shearing Action and Chemical Additive". figshare. https://hdl.handle.net/2134/26484. 


\title{
Devulcanization and recycling of waste automotive EPDM rubber powder by using shearing action and chemical additive
}

\author{
S. Ostad Movahed ${ }^{1 *}$, A. Ansarifar ${ }^{2}$, S. Karbalaee ${ }^{1}$, S. Athary far ${ }^{1}$ \\ ${ }^{1}$ Polymer group, Faculty of Sciences, Ferdowsi University of Mashhad, Mashhad, Iran \\ ${ }^{2}$ Department of Materials, Loughborough University, Leicestershire LE11 3TU UK
}

\begin{abstract}
In automotive applications, ethylene-propylene-diene rubber (EPDM) is used to manufacture various components and therefore recycling scrap rubber is a major issue. The primary aim of this study was to develop a new method for devulcanizing waste automotive EPDM rubber powder by using shearing action and chemical additive and recycle the devulcanized powder. A semi-industrial twin screw extruder with a shearing action and reactor along with 2mercaptobenzothiazole-disulfide (MBTS) chemical were used to devulcanize the waste powder at two different feed screw speeds and main rotor speeds at a constant temperature of $220^{\circ} \mathrm{C}$. To recycle the devulcanized powder, different amounts of the devulcanized powder were mixed with a commercial EPDM-based automotive rubber strips compound to produce blends. The blends, commercial compound and devulcanized powder were cured with a semi-efficient (SEV) vulcanization system and their viscosity, cure and mechanical properties measured. For the blends, the Mooney viscosity was unchanged with 40 wt\%, crosslink density with 20 wt\%, tensile strength and elongation at break with $10 \mathrm{wt} \%$, and compression set with $20 \mathrm{wt} \%$ of the devulcanized powder. Interestingly, the hardness benefitted from $50 \mathrm{wt} \%$ of the devulcanized powder in the blends. The scorch and optimum cure times shortened and the cure rate index rose when the loading of the devulcanized powder in the blends was raised. This new method offered a major new route for devulcanizing and recycling the waste powder.
\end{abstract}

* Correspondence to: S.Ostad Movahed (s-ostad@um.ac.ir) 


\section{INTRODUCTION}

One of the problems that humanity faces as it enters the 21st century is waste disposal management. Polymeric materials do not decompose easily and therefore disposal of waste polymers is a serious environmental concern. Rubber recycling is growing in importance worldwide because of increasing raw material costs, diminishing resources, and the growing awareness of environmental issues and sustainability ${ }^{1}$. One of the major problems until now has been the limited use of recycled rubber in real recycling loops, for example, reuse in new rubber products. Improvement of the properties of recycled rubber by developing a more selective breakdown process is an important issue and a global challenge ${ }^{2}$. ASTM STP 184 A defines devulcanization as "a combination of depolymerization, oxidation, and increased plasticity" because each of these processes usually occurs during reclamation ${ }^{3}$. Actually, devulcanization is the reverse of vulcanization.

In sulfur vulcanization, the formation of both $\mathrm{C}-\mathrm{S}$ and $\mathrm{S}-\mathrm{S}$ bonds takes place, and it is therefore expected that during devulcanization, only $\mathrm{C}-\mathrm{S}$ and $\mathrm{S}-\mathrm{S}$ bond cleavage should occur. In fact, in an ideal devulcanization process, crosslinks should be broken without main-chain scission. Ethylene-propylene-diene rubber (EPDM; Scheme 1) was first introduced in the USA, in limited commercial quantities in $1962^{4}$. EPDM is a copolymer of ethylene and propylene with a diene monomer. The diene introduces unsaturation sites or double bonds into the macromolecule. Currently, EPDM is the fastest-growing general purpose rubber. This is because EPDM has excellent properties particularly good resistance to ozone and ability to tolerate high loading of solid fillers. In automotive applications, about $3 \mathrm{wt} \%$ of the total weight of a vehicle corresponds to non-tire rubber products, namely, weather-strips, hoses, vibration insulators, and miscellaneous parts. Since the beginning of the production and use of rubber products such as vulcanized filled EPDM rubbers, the disposal of scrap or used rubber parts has been a problem. Devulcanization processes, during which the destruction of the rubber network takes place, may be classified into five groups ${ }^{5}$ :

- chemical processes

- thermochemical processes

- mechanical processes

- irradiation processes 
- biological processes

A typical chemical process involves the mixing of rubber scrap powders with reclaiming agents such as disulfides, thiophenols, and their zinc salts, and mercaptans. ${ }^{6}$ The reclaiming agent breaks down the rubber network. In thermochemical processes, a combination of heat and reclaiming agents is used to break the crosslinking points. ${ }^{7,8}$ In mechanical processes, a shearing action is applied which tears the rubber network. Shearing can be created by two roll mills ${ }^{9-11}$, a batch mixer ${ }^{4}$, and a single- or twin-screw extruder ${ }^{12-16}$. Irradiation processes include microwave ${ }^{17-21}$ and ultrasonic wave devulcanization ${ }^{22,23}$. The three-dimensional rubber network can be broken down by microwaves and ultrasonic waves. In terms of environmental conservation, biological processes (microbial metabolism) are useful for devulcanization. ${ }^{24,25}$ Some microbes exhibit biological activity toward sulfur and break the sulfur crosslinks in rubber by oxidizing sulfur to sulfate and hence waste rubber products are devulcanized by various Thiobacillus species. However, this method is slow, time consuming, and has low conversion efficiency. Other miscellaneous methods such as devulcanization in supercritical materials are also available but not of industrial importance yet ${ }^{26}$.

\section{Recycling of EPDM rubber}

Recycling of EPDM rubber can involve reprocessing it into its virgin form by breaking down the crosslinks between the polymer chains (devulcanization), or, reusing the EPDM waste in a useful form. There are various difficulties associated with the recycling of EPDM that includes the low solubility of most devulcanizing agents in the rubber matrix and presence of a higher percentage of stable monosulfidic crosslinks in the rubber ${ }^{27}$. The energies required to break monosulfidic CS, polysulfidic S-S and peroxide C-C bonds are 270,240 and $345 \mathrm{~kJ} / \mathrm{mol}$ respectively ${ }^{28}$. Isayev et $a l^{29-30}$ investigated the devulcanization of various rubbers including EPDM in a reactor consisting of a single screw extruder and an ultrasonic source on the die. The effects of processing parameters and ultrasonic conditions on devulcanization were reported. Mouri et al. ${ }^{31}$ used a chemico-mechanical method involving simultaneous use of a chemical devulcanizing agent and shear stress. The devulcanization efficiency was increased by the addition of the chemical agents during shearing action. ${ }^{13,27,31,32}$ The chemical agents were organic disulfides, mercaptanes and aliphatic amines. Their work clearly showed that the use of chemical additives during the shearing action was effective in devulcanizing the waste rubber. However, influence 
of other factors such as different feed screw speeds and main rotor speeds on the devulcanization process of the waste rubber powder at a constant temperature were not investigated. These factors could have significant effect on the efficiency of the process and merit further investigation.

The primary aim of this study was to develop a new method for devulcanizing waste EPDM rubber powder obtained from automotive parts and recycle the devulcanized powder in a commercial compound suitable for making automotive parts. The novel feature of this study was the use of different feed screw speeds and main rotor speeds during the devulcanization of the waste rubber at a constant temperature. The main objectives were:

- to devulcanize the waste power with a semi-industrial twin screw extruder that used a shearing action and reactor along with 2-mercaptobenzothiazoledisulfide (MBTS) chemical (Scheme 2). This was carried out at feed screw speeds of 6 and $8 \mathrm{rpm}$, main rotor speeds of 180 and $220 \mathrm{rpm}$ at a constant temperature of $220^{\circ} \mathrm{C}$.

- to recycle the devulcanized waste powder by mixing different amounts of the devulcanized powder with a commercial EPDM-based automotive rubber strips compound (referred to as reference compound) to produce 8 blends. The blends, reference compound and devulcanized powder were then cured with a semi-efficient (SEV) vulcanization system. The viscosity, cure and mechanical properties of the blends were measured and compared with those of the reference compound to assess effect of the increasing amount of the devulcanized powder in the blends on the aforementioned properties.

\section{EXPERIMENTAL}

\section{Materials - Rubber, filler and rubber chemicals}

Composition of the waste EPDM rubber powder - Waste EPDM rubber powder was obtained from the Part Lastic Company, Iran. This powder was a mixture of several aged and new rubber automotive rubbers with average particle size less than $1 \mathrm{~mm}$. In the first stage, the oil content was extracted using a Soxhlet apparatus. The extraction was performed using acetone (300 ml) and $100 \mathrm{~g}$ of rubber sample for $16 \mathrm{~h}$ at $70{ }^{\circ} \mathrm{C}$, as described in ASTM D297-93. After extraction, the rubber sample was dried in an oven with circulating air for $12 \mathrm{~h}$. The average of five extraction experiments showed that the waste EPDM rubber powder had a median oil content of 
about $17.42 \mathrm{wt} \%$. In the next stage, thermogravimetric analysis (TGA; STA 1500, Scinco Co., Ltd.) was used to determine the composition of the acetone-extracted waste rubber powder. TGA was performed in a nitrogen atmosphere and in air at temperatures below and above $550{ }^{\circ} \mathrm{C}$, respectively. The TGA curve and corresponding compositions are shown in Fig. 1 and Table 1.

The other ingredients used were EPDM ( KEP 270, 57 wt\% ethylene and $4.5 \%$ diene monomer; KUMHO POLYCHEM , Korea), carbon black ( N330, filler; Pars Carbon Ltd., Saveh ), 2-mercaptobenzothiazole disulfide (Perkacit MBTS, devulcanizing agent and accelerator; Flexsys), tetramethylthiuram disulfide (Perkacit TMTD, devulcanizing agent and accelerator, Scheme 3; Flexsys), zinc dibutyl dithiocarbamate (Perkacit ZDBC, accelerator; Flexsys), zinc oxide (activator; Harcros Durham Chemicals, UK), stearic acid (activator; Anchor Chemicals Ltd., UK), elemental sulfur (curing agent; Solvay Barium Strontium, Hannover, Germany), and aromatic and aliphatic oils as processing aids (Mehran Tyre 290 and Fariman, Iran).

\section{Sample preparation and devulcanization method}

To devulcanize the waste rubber powder, MBTS, aromatic oil and paraffinic oil (Table 2) were placed in a simple mixer equipped with agitator. The waste rubber powder was immersed in oil for $24 \mathrm{~h}$ to allow it to penetrate into the rubber. Devulcanization was subsequently carried out in a semi-industrial twin screw extruder (CTE 65-52D, Coperion Keya Nanjing machinery Co. Ltd) with a capacity of 100-250 kg/h (Fig. 2). The machine was equipped with a feeder with adjustable feed rate screw, cooling and heating systems as well as a main screw with rotating speed control. ${ }^{33}$ Compounds approximately $40 \mathrm{~kg}$ in weight were fed into the extruder hopper and then screw began to turn. Compound A and Compound B were made by devulcanizing the waste powder at two different feed screw speeds and main screw speeds as shown in Table 3. Figure 3 shows the final product (compound A) at the end of the process.

After devulcanization (Table 4), different amounts of Compound A and Compound B were mixed with the virgin EPDM rubber, carbon black and oil for about 4.5 minutes in a laboratory Banbury mixer (1.5 l capacity, Werner Pfleiderer) with counter rotating tangential rotors. In these experiments, the rotors speed was set at $40 \mathrm{rpm}$, the mixing chamber's initial and final temperatures were set at 40 and $85{ }^{\circ} \mathrm{C}$, respectively and the chamber was $80 \%$ full. The required 
amounts of carbon black and oil were calculated taking into account the amount of Compound A and Compound B present in the blends and then added in one stage. Note that the chemical ingredients, i.e. carbon black and oil were from a reference compound with a common formulation (Tables 5 \& 6) that is used to manufacture automotive rubber strips (Part Lastic Company, Iran). A computer software was used for controlling the mixing condition and storing data. The compound temperature as a function of mixing time for the blends and the reference compound are shown in Figures 4 and 5.

In the final stage, the curing chemicals were added to the rubber blends on a two roll mills with rolls $14 \mathrm{~cm}$ in diameter and $32 \mathrm{~cm}$ long and mixed for $5 \mathrm{~min}$. Both, the Banbury mixer and two roll mills were equipped with cooling systems. The required amount of the chemicals needed to cure each rubber blend was calculated based on the loading of Compound A and Compound B present in the blends. The final formulations of the blends made of Compound A, virgin rubber, and chemical ingredients were labelled A-1 to A-4, and those made of Compound B, virgin rubber, and chemical ingredients labelled B-1 to B-4. Also, the devulcanized waste powder was mixed with appropriate amounts of the chemical ingredients (Tables 5 \& 6) and tested for its properties.

\section{Viscosity and cure properties of the rubber compounds}

The viscosity of the rubber compounds was measured at $125^{\circ} \mathrm{C}$ in a single-speed rotational Mooney viscometer (SANTAM SRT-200B, Santam Company) according to the procedure described in British Standard ${ }^{34}$. The results, Mooney units (MU), were expressed as a function of the wt\% of compound A and compound B in the blends in Fig. 6. The scorch time $\left(t_{s 1}\right)$, which is the time for the onset of cure, the optimum curing time $\left(t_{90}\right)$, which is the time for completion of cure, and $\Delta$ torque, which is the difference between the maximum and minimum torques on the cure trace of the rubber and is an indication of the crosslink density changes were determined from the cure traces generated at $180 \pm 2{ }^{\circ} \mathrm{C}$, using an oscillating disk rheometer curemeter (ODR, SANTAM SRT-200B, Santam Company) at an angular displacement of $\pm 3^{\circ}$ and a test frequency of $1.7 \mathrm{~Hz}$. The rheometer tests were performed for up to $3 \mathrm{~min}$. The cure rate index, which is a measure of the rate of cure in the rubber, was calculated using the following equation: 


$$
\mathrm{CRI}=100 /\left(t_{90}-t_{s 1}\right)
$$

The $\Delta$ torque, $\mathrm{t}_{\mathrm{s} 1}$, $\mathrm{t}_{90}$, and CRI of the rubber compounds were plotted against wt $\%$ of the Compound A and Compound B in the blends and shown in Figs. 7-11.

\section{Curing of the rubber compounds, test pieces and test procedure}

After the optimum cure times were measured, the rubber compounds were cured in a compression mould at $180^{\circ} \mathrm{C}$ and a pressure of $160 \mathrm{~atm}$. Pieces of rubber, each approximately $57 \mathrm{~g}$ in weight, were cut from the milled sheets. Each piece was placed at the centre of the mould to enable it to flow in all directions when pressure was applied. This prevented anisotropy from forming in the cured rubber. Sheets $15 \mathrm{~cm}$ by $15 \mathrm{~cm}$ in dimensions and approximately $2.3 \mathrm{~mm}$ thick were used for measuring the tensile strength, elongation at break, modulus, hardness, tear strength, and compression set of the cured rubber compounds.

\section{Crosslink density, rubber density, extent of devulcanization and sol gel \% measurements}

The solvent used for the sol gel \% and crosslink density (CLD) determinations was toluene. For the determination, $5 \mathrm{~g}$ of rubber was placed in $300 \mathrm{ml}$ of the solvent in labelled bottles, and allowed to swell for $16 \mathrm{~d}$ at $21^{\circ} \mathrm{C}$. The weight of the sample was measured every day until it reached equilibrium. The solvent was then removed. The samples were dried in air for $9 \mathrm{~h}$ and then in an oven at $85^{\circ} \mathrm{C}$ for $24 \mathrm{~h}$, and allowed to stand for an extra $24 \mathrm{~h}$ at $23^{\circ} \mathrm{C}$ before reweighing. The CLD was then calculated using the Flory-Rehner equation: ${ }^{35}$

$$
\rho_{c}=-\frac{1}{2 V_{s}} \frac{\ln \left(1-v_{r}^{0}\right)+v_{r}^{0}+x\left(v_{r}^{0}\right)^{2}}{\left(v_{r}^{0}\right)^{1 / 3}-v_{r}^{0} / 2}
$$

where $\rho_{c}$ is the $\operatorname{CLD}\left(\mathrm{mol} / \mathrm{m}^{3}\right), V_{s}$ is the molar volume of toluene $\left(1.069 \times 10^{-4} \mathrm{~m}^{3} / \mathrm{mol}\right.$ at $\left.25^{\circ} \mathrm{C}\right)$, $v_{r}^{0}$ is the volume fraction of rubber (polymer) in the swollen gel, and $\chi$ is the interaction parameter, which was calculated using the following equations: ${ }^{36,37}$

$$
\begin{gathered}
\chi=0.429+0.218 v_{r}^{o} \\
v_{r}^{o}=\frac{1}{1+\frac{d_{r}}{d_{s}}\left(\frac{1-f_{s o l}}{1-f_{\text {sol }}-f_{f i l}}\right)\left(\frac{w_{s}}{w_{0}}-1\right)}
\end{gathered}
$$


where $d_{r}$ and $d_{s}$ are the densities of the rubber and solvent, respectively, $f_{\text {sol }}$ is the weight fraction of soluble material in the initial sample (sol fraction), $f_{f i l}$ is the initial weight fraction of filler in the sample, $w_{s}$ is the weight of the swollen gel, and $w_{0}$ is the weight of the dried sample.

The sol gel and devulcanization \% were calculated as follows:

$$
\text { Sol gel percent }=f_{\text {sol }} X 100=\frac{w_{i}-w_{0}}{w_{i}} X 100
$$

Devulcanization $(\%)=100 \times($ initial waste rubber CLD - final rubber CLD)/initial waste rubber

CLD

where $w_{i}$ is the initial weight of the sample. The initial waste rubber CLD was chosen to be 186 $\mathrm{mol} / \mathrm{m}^{3}$ (Table 1). The density of compounds was measured according to ASTM D297- 13, using methanol and a Pycnometer as follow:

$$
\rho(g r / c c)=\frac{A}{A-(B-C)} \times \rho(\text { Methanol })
$$

where A, B and C are initial sample weights $(1 \mathrm{~g})$, the weight of methanol-filled pycnometer with sample and the weight of methanol-filled pycnometer without sample, respectively. Devulcanization \%, sol gel content \%, densities and crosslink densities of the devulcanized compounds A and B were shown in Table 4.

\section{Tensile property, tear strength, hardness and compression set of the rubber compounds}

The tensile strength, elongations at break, and modulus at different elongations of the rubber vulcanizates were determined in uniaxial tension using dumbbell test pieces, $95 \mathrm{~mm}$ long with a central neck $26 \mathrm{~mm}$ long and $2.3 \mathrm{~mm}$ wide, in a SANTAM STM-20 mechanical testing machine. The test pieces were die-stamped from the sheets of cured rubber. The tests were performed at $21^{\circ} \mathrm{C}$ and a cross-head speed of $500 \mathrm{~mm} / \mathrm{min}^{38}$ SANTAM computer software was used for storing and processing the data. Figs. 12-15, show tensile strength, elongation at break and modulus of the blends as a function of wt \% of the Compound A and Compound B in the blends.

The hardness was measured using cylindrical samples $12.5 \mathrm{~mm}$ thick and $29.0 \mathrm{~mm}$ in diameter. ${ }^{39}$ The samples were placed in a Shore A durometer hardness tester (Shore Instrument \& Mfg., Co., New York) and the hardness was measured at $23.5^{\circ} \mathrm{C}$ and a reading was taken after 
$15 \mathrm{~s}$. This was repeated on three different positions on each sample and the median of the three readings were recorded (Fig. 16).

The tear strength of the cured rubbers was determined in uniaxial tension at an angle of $180^{\circ}$, at ambient temperature $\left(21^{\circ} \mathrm{C}\right)$ and at a constant cross-head speed of $500 \mathrm{~mm} / \mathrm{min}^{40}$ in a SANTAM STM-20 mechanical testing machine. For these tests, rectangular test strips $60 \mathrm{~mm}$ long and $9 \mathrm{~mm}$ wide were used. Strips were cut from the cured sheets of rubber and a sharp crack approximately $5 \mathrm{~mm}$ in length was introduced into the strips half way along the width and parallel to the length of the strip to form the trouser test pieces for the tear experiments. The results were summarized in Fig. 17.

The compression set was determined in a compression set testing machine (Taha Ghaleb Tools Co.) at $25 \%$ compression for $24 \mathrm{~h}$ at $100^{\circ} \mathrm{C}$, using cylindrical samples $12.5 \mathrm{~mm}$ thick and $29.0 \mathrm{~mm}$ in diameter according to the procedure described in ASTM D395-03. At the end of each test, the sample was removed and allowed to cool down at room temperature for $30 \mathrm{~min}$ before the set was measured using the following formula:

$$
\text { Compression set }=\frac{\text { Initial thickness-Final thickness }}{0.25 \times \text { Initial thickness }} X 100
$$

This was repeated for three different samples and the median of three readings was reported (Fig. 18).

\section{Assessment of the microstructure and dispersion of carbon black filler in the rubber compounds} Dispersion of the filler particles and other impurities in the rubber was assessed by a LEO 1530 VP field emission gun scanning electron microscope (SEM). Small pieces of the uncured rubber were placed in liquid nitrogen for $3 \mathrm{~min}$ and then fractured to create two fresh surfaces. The samples, $60 \mathrm{~mm}^{2}$ in area and $5 \mathrm{~mm}$ thick, were coated with gold and then examined and photographed in the SEM. The degree of dispersion of the filler particles and other impurities in the rubber was subsequently studied from the SEM micrographs shown in Figs. 19-23.

\section{RESULTS AND DISCUSSION}

\section{Devulcanization process of the waste rubber powder}


Table 1 and Fig. 1 show the TGA results for the acetone-extracted waste rubber powder. The results showed that EPDM degradation began at $287.6^{\circ} \mathrm{C}$ and finished at $547.8^{\circ} \mathrm{C}$. Mass loss was also observed in the range $26.2-287.6^{\circ} \mathrm{C}$ because of the presence of the oil. In addition to the mass loss related to the oil and rubber, a transition in the range of 550-613 ${ }^{\circ} \mathrm{C}$ was observed. This was attributed to the combustion of carbon black present in the sample (after changing the atmosphere to air at $550{ }^{\circ} \mathrm{C}$ ). The unburned residue was attributed to minerals and metal present in the sample. Only $38.88 \mathrm{wt} \%$ of the residue or exactly $32.1 \mathrm{wt} \%$ of the initial waste powder (before acetone extraction) was rubber. An effective reclaiming agent was therefore needed for the efficient devulcanization of the waste powder. Several researchers found that tetramethylthiuram disulfide (TMTD) (Scheme 3) was an efficient devulcanizing agent. ${ }^{10-11}$ However, the authors observed no significant devulcanization of the waste powder with TMTD and therefore no results from the tests with TMTD were included here.

Figure 2 shows the twin screw extruder (devulcanization reactor) along with the corresponding water bath that was used for cooling the devulcanized profile from the reactor temperature at $220^{\circ} \mathrm{C}$ to ambient. The geometry and configuration of the screw along with the rate of feeding raw material into the extruder hopper and subsequently to the screw channel were important factors in devulcanizing rubber and producing a continuous profile flow. There were two major zones in the screw channel. In the first zone, rubber was reduced to fine particles and heated to the devulcanization reaction temperature at $220^{\circ} \mathrm{C}$ and in the second zone, the rubber devulcanization reaction took place with the aid of both shearing action and MBTS devulcanizing agent. In the first zone, the coarsely crushed rubber loaded into the screw channel was reduced to fine particles by the shearing action of the screw which compressed and heated it quickly to the processing temperature, and then fed it into the devulcanizing reaction zone. In the devulcanizing reaction zone, the flow of the rubber was restricted and the fill factor inside the reaction zone was increased. Hence, the rubber became highly compressed and the hydrostatic pressure acting on it increased. The devulcanized rubber was obtained continuously at the head of the reactor in the form of strand. The surface appearance of the devulcanized rubber depended strongly on the devulcanization condition namely, screw speed, temperature of the screw channel (devulcanization temperature), feeding rate and raw material composition. When the operating conditions were not optimal, the surface of the strand appeared rough. 
Considering these facts and keeping in mind the poor quality of the used waste rubber (Table 1) and feed composition (Table 2), the authors repeated several experiments and found that at 180 and $220 \mathrm{rpm}$ main screw speeds and a temperature of $220^{\circ} \mathrm{C}$ along with feed screw speeds of 6 and $8 \mathrm{rpm}$, an optimum condition for producing a continuous and smooth devulcanized rubber surface was achievable (Table 3 and Fig. 3). The feed composition consisted of $100 \mathrm{phr}$ EPDM waste rubber powder, $6 \mathrm{phr}$ MBTS, and a total amount of $15 \mathrm{phr}$ of aromatic and aliphatic oils. This formulation combined with the mixing condition described above showed the highest devulcanization \% of the waste powder. The oil played several roles in the devulcanization process apart from raising the plasticity of the devulcanized rubber. For example, it accelerated oxidation of the rubber and prevented gel from forming by acting as a radical acceptor. ${ }^{41}$ This material also swelled the polymer matrix and increased the polymer chains mobility, resulting in easier crosslinks cleavage during devulcanization. Reclaiming oils with a high compatibility was therefore used in the formulations of Compound A and Compound B. Table 4 showed 92.19 and 91.85 \% devulcanization for Compound A and Compound B, respectively, which indicated that MBTS was an effective devulcanizing agent. In addition, these results showed reduction in the crosslink density from $186 \mathrm{~mol} / \mathrm{m}^{3}$ (Table 1 ) to 14.5 and $15.16 \mathrm{~mol} / \mathrm{m}^{3}$ (Table 4) and increase in sol gel content from 0.5 to 17.6 and $13.1 \%$ for initial waste rubber powder and devulcanized Compound A and Compound B, respectively. MBTS, similar to most accelerators melts above $100{ }^{\circ} \mathrm{C}$ but decomposes above $200^{\circ} \mathrm{C} .{ }^{42}$ The large shearing action broke down both the polymer chains and chemical crosslinks when devulcanization was performed in the presence of MBTS in a twin screw extruder. Simultaneously, the shearing action broke the MBTS molecules to form corresponding radicals (Scheme 4).

MBTS formed radicals were more stable than the TMTD ones due to the potential resonance stabilization of the radicals that appreciably weakened the central S-S bond in the structure of the devulcanizing agent and facilitated the formation of radicals. These radicals were then combined with the broken polymer chain radicals and produced an accelerator-terminated polysulfidic pendant group of polymer chains that were ready for revulcanization (Scheme 4). The sol gel \%, crosslink density and devulcanization \% of Compound A were $17.6 \%, 14.50$ $\mathrm{mol} / \mathrm{m}^{3}$ and $92.19 \%$, respectively, and those of Compound B, $13.1 \%, 15.16 \mathrm{~mol} / \mathrm{m}^{3}$ and $91.85 \%$, respectively (Table 4). Compound A was slightly better devulcanized than Compound 
B. It seemed that a longer residence time in the screw channel caused by a lower screw speed at $180 \mathrm{rpm}$ was more beneficial to the devulcanization process. However, on an industrial scale the higher residence time for a compound in the screw channel is not desirable because it reduces the production rate.

\section{Compound temperature, Mooney viscosity and cure properties of the blends}

Figures 4-5 show compounds temperature vs. mixing time during the blending of Compound A and Compound B with the virgin EPDM rubber, carbon black and oil in the Banbury mixer. As the results showed, the compound temperature increased progressively as a function of mixing time for all the blends as well as the reference compound and Compound A tested. The largest increase in temperature as a function of mixing time was recorded for the reference compound from 40 to $83^{\circ} \mathrm{C}$. However, for the blends, the compound temperatures at the start of mixing were noticeably higher than that of the reference compound. For example, for the A-1 blend, the compound temperature rose from approximately 53 to $83^{\circ} \mathrm{C}$ as a function of mixing time and as the amount of Compound $\mathrm{A}$ in the blend was increased further to its highest level (blend A-4), the compound temperature at the start of mixing was $68^{\circ} \mathrm{C}$ and then rose to $81^{\circ} \mathrm{C}$ after mixing ended (Fig. 4). A similar trend was also observed for the B-1 to B-4 blends (Fig. 5). It appeared that increase in the amount of Compound A or Compound B in the blend caused a much higher temperature at the start of mixing and then the optimum temperature reached after a shorter mixing time when compared with the reference compound. This trend was similar for all the blends tested.

Figure 6 shows Mooney viscosity as a function of wt \% of Compound A and Compound B in the blends. The reference compound had a viscosity of about $57 \mathrm{MU}$. However, as the amount of Compound A in the blend was increased to about $50 \mathrm{wt} \%$, the viscosity increased to $62 \mathrm{MU}$ and then it decreased quite dramatically to about $30 \mathrm{MU}$ when the amount of Compound $\mathrm{A}$ in the blend was raised to $100 \mathrm{wt} \%$. Similarly, when the amount of Compound B in the blend was raised to about $30 \mathrm{wt} \%$, the viscosity rose to $60 \mathrm{MU}$ and then dropped to $24 \mathrm{MU}$ as the amount of Compound B in the blend reached $100 \mathrm{wt} \%$. These reductions were due to the fact that the rubber chains in Compound A and Compound B underwent significant chain scission during the shearing action in the extruder whilst devulcanizing and became softer. Therefore, as the amount 
of Compound A and Compound B in the blends was increased, the blends became softer and viscosity decreased.

After the cure properties of the rubber compounds were measured, the results were plotted against the amount of Compound A and Compound B in the blends. Figure 7 shows $\Delta$ torque as a function of wt $\%$ of Compound $\mathrm{A}$ in the blend. The $\Delta$ torque remained unchanged with up to 20 wt\% of Compound A in the blend. However, a large drop was observed when Compound A in the blend reached its full amount. Clearly, increase in the amount of Compound $\mathrm{A}$ in the blend above $20 \mathrm{wt} \%$ was not beneficial to the crosslink density of the blend. The cure times, $\mathrm{ts}_{1}$ and $\mathrm{t}_{90}$ were also affected by increase in the amount of Compound $\mathrm{A}$ in the blend though not in the same way. As Fig. 8 shows, $t_{s 1}$ and $t_{90}$ decreased as the amount of Compound $\mathrm{A}$ in the blend was increased to its optimum amount and hence this was beneficial to the cure cycle which was made much shorter. A similar trend was also observed for the blends containing an increasing amount of Compound B.

Figure 9 shows $\Delta$ torque as a function of wt $\%$ of Compound B in the blend. There was no adverse effect on the crosslink density for up to $20 \mathrm{wt} \%$ of Compound B in the blend but $\Delta$ torque dropped significantly when the weight of Compound B reached $100 \mathrm{wt} \%$. The cure time had benefitted from the addition and progressive increases in the amount of Compound $\mathrm{B}$ in the blend as shown by large reduction in this property. It is interesting to note that the cure rate index (CRI), which is a measure of the rate of cure in the rubber, had risen so much particularly above 50 wt \% of Compound A and Compound B in the blends (Fig. 11). This meant a faster cure and a much shorter cure cycle. The reason that the CRI increased was probably due to the presence of higher active crosslinking sites in the blends when compared with the reference compound. ${ }^{13}$

\section{Mechanical properties of the rubber compounds}

The mechanical properties of the rubber compounds as reported in Figs. 12-18 were influenced substantially by the amount of Compound A and Compound B in the blends. The tensile strength decreased by almost $87 \%$ (Fig. 12) and elongation at break by $82 \%$ (Fig. 13) when the amount of Compound A and Compound B in the blends reached their optimum amounts. The modulus deteriorated when the amount of Compound A and Compound B in the blends was raised to it optimum. For example, the reference compound had a modulus of $11 \mathrm{MPa}$ and when Compound 
A and Compound B were added, the modulus dropped to as low as $2 \mathrm{MPa}$. It was also noted that the modulus was much higher at larger elongation of the rubber. The modulus at $100 \%$ elongation was around 6.5 MPa, whereas at $20 \%$ elongation, it was $3 \mathrm{MPa}$ (Figs. 14 \&15). Clearly, the modulus did not benefit from mixing the reference compound with any amounts of Compound A or Compound B.

The hardness improved when the amount of Compound A and Compound B in the blends was increased to about $40 \mathrm{wt} \%$ and then there was a large drop in the values recorded though the blend with Compound A remained harder at the highest loading of the Compound (Fig. 16). The tear strength showed a significant deterioration, i.e. by almost $80 \%$, when the amounts of Compound A and Compound B in the blends were raised to their optimum levels (Fig. 17).

Compression set is an important property in the gasket industry and is measured as the ratio of elastic to viscous components of a rubber response to a given deformation. ${ }^{43}$ The results for compression set were interesting too. First, the compression set increased from 68 to $69 \%$ when the amount of Compound A and Compound B in the blends reached $10 \mathrm{wt} \%$. Thereafter, it dropped to its lowest value at about 59\% and then increased nearly to its original value, i.e. at 70\%, when the full amount of Compound A and Compound B were added to the blends. Therefore, at $20 \mathrm{wt} \%$ of Compound A, the blend had its lowest compression set (Fig. 18).

It seemed that higher loading of the devulcanized waste powder (either Compound A or Compound B) was not generally beneficial to the mechanical properties of the blends but lower amounts were. Apparently, the viscosity was unaffected with $40 \mathrm{wt} \%$ (Fig. 6), crosslink density with $20 \mathrm{wt} \%$ (Figs. 7 \&9) , tensile strength with $10 \mathrm{wt} \%$ (Fig. 12), elongation at break with $10 \mathrm{wt} \%$ (Fig. 13), and hardness with $50 \mathrm{wt} \%$ (Fig. 16) of the devulcanized waste powder in the blends. The scorch and optimum cure times and cure rate index were the biggest beneficiaries of adding the devulcanized waste powder to the reference compound because the cure cycle became a lot shorter.

\section{Examination of the microstructures of the rubber compounds with SEM}

Figures 19-23 show SEM micrographs of the rubber compounds tested. The mechanical properties were always affected by the resulting morphology of the blends. ${ }^{44-45}$ The full dispersion of the filler particles in the rubber helped to maximize the reinforcing effect of the 
filler on the mechanical properties of the cured rubbers. ${ }^{46}$ Figure 19 shows carbon black dispersion in the rubber matrix with the average particle size around $20 \mu \mathrm{m}$ for the reference compound. In addition to the filler, some other impurities were also present in the rubber.

According to the TGA results (Table 1), approximately $15.5 \%$ of the residue was non rubbery. When rubber waste was originally grinded to produce powder, the process could have been contaminated with metal which was present in the process. This might have introduced impurities and contamination into the final product and these were showing as white spots on the micrographs. In such processes contamination can never be eliminated. There were also cavities (Fig. 20), which could have caused areas of weakness in the rubber and hence lower tensile strength of the cured rubber. The presence of these cavities in the rubber matrix was not desirable. ${ }^{47}$ Figures 21-23 show the internal structures of the rubber as the amounts of Compound A and compound B in the blends were increased. There was no noticeable difference between the microstructures of the blends.

As mentioned earlier, there are various methods for devulcanizing waste EPDM rubber. Thermo-mechanical shearing devulcanization method has proved to be very effective in destroying the crosslinked structure and restoring to ground rubber a certain extent of plasticity and processability. ${ }^{13,27,31,32}$ There was also relationship between the devulcanization level as indicated by gel fraction and crosslink density and mechanical properties. ${ }^{48}$ Our results are in line with the previous findings. Probably the most interesting aspect of our results was the fact that different feed screw speeds and main rotor speeds did increase the efficiency of the devulcanization process of the waste rubber powder at a constant temperature. In fact, the authors found that at 180 and $220 \mathrm{rpm}$ main rotor speeds and a temperature of $220^{\circ} \mathrm{C}$ along with feed screw speeds of 6 and $8 \mathrm{rpm}$, an optimum condition for producing a continuous and smooth devulcanized rubber surface was achievable. This was an interesting finding.

\section{CONCLUSIONS}

From this study, it was concluded that:

- A semi-industrial twin screw extruder with a shearing action and reactor along with 2mercaptobenzothiazoledisulfide (MBTS) was an efficient and practical method for devulcanizing waste automotive EPDM rubber powder. The process was carried out at $220^{\circ} \mathrm{C}$ with the feed 
screw speed set at 6 and $8 \mathrm{rpm}$ and main screw speed set at 180 and $200 \mathrm{rpm}$ to devulcanize the waste rubber.

- When the devulcanized waste powder was mixed with the virgin EPDM rubber, carbon black and oil to produce blends, the compound temperature increased as a function of mixing time. The blends containing the largest amounts of the devulcanized waste powder had the highest initial temperature and then reached their optimum temperatures after a shorter mixing time when compared with the reference compound.

- The Mooney viscosity remained unchanged when up to $40 \mathrm{wt} \%$ of the devulcanized waste powder was in the blends. However, the viscosity decreased very substantially when the loading of the devulcanized waste powder in the blends was raised to its optimum. Lower viscosity was very beneficial for the ease of processing.

- The $\Delta$ torque which indicated crosslink density changes in the rubber was unaffected with $20 \mathrm{wt} \%$ of the devulcanized waste powder (either Compound A or Compound B) in the blends.

- The elongation at break was unaffected with $10 \mathrm{wt} \%$, hardness with $50 \mathrm{wt} \%$, compression set with $20 \mathrm{wt} \%$, and tensile strength with $10 \mathrm{wt} \%$ of the devulcanized powder in the blends.

- The scorch and optimum cure times shortened and the cure rate index increased for the blends containing an increasing loading of the devulcanized powder.

In summary, the results indicated that this semi-industrial twin screw extruder with a shearing action and reactor along with 2-mercaptobenzothiazole-disulfide (MBTS) provided a major new route for devulcanizing the waste automotive EPDM rubber powder that could then be reused or recycled in the commercial EPDM-based automotive rubber strips compound. However, to optimise the benefits, it was essential to adjust the amount of the devulcanized waste powder in the commercial rubber strips compound accurately to achieve the best possible effect on a particular property. This was similar to the findings reported previously where processing, cure characteristics and mechanical properties of EPDM rubber vulcanizate were affected by the level of the devulcanized waste rubber. ${ }^{49}$ 


\section{ACKNOWLEDGEMNT}

This work was carried out in collaboration with Part Lastic Companies group. The authors sincerely thank them for their cooperation.

\section{REFERENCES}

1. M. Myhre, S. Saiwari, W. Dierkes, J. Noordermeer, Rubber. Chem. Technol. 85 (2012), 408.

2. European Tire Recycling Association (ETRA), Introduction to Tire Recycling, V.L. Shulman, Ed., (2008).

3. ASTM Spec. Tech. Publ. N184A ,29 (1987).

4. P. Sutanto, F.L. Laksmana, F. Picchioni, L.P. Janssen. Chem. Eng. Sci. 61 (2006), 6442.

5. M. Luo, X. Liao, S. Liao, Y. Zhao, Adv. Mat. Res. 181 (2012), 554.

6. W.C. Warner. Rubber Chem. Technol. 67 (1994), 559.

7. H.J. Manuel, W. Dierkes. Rapra Review Reports. 99 (1999).

8. J.P. Paul, Chemtech. 9 (1979),104.

9. Deb. De, D. De, G.M. Singharoy. Polym. Eng. Sci. 47 (2007),1091.

10. D. De, A. Das, Deba. De, B. Dey. Eur. Polym. J. 42 (2006), 917.

11. Deb. De, D. De. Mat. Sci. \& Appl. 2 (2011), 486.

12. H. Yazdani, I. Ghasemi, M. Karrabi, H. Azizi, G. Bakhshandeh. J. Vinyl and Add. Technol. 19 (2013), 65.

13. P. Sutanto, F. Picchioni, L. Janssen, A. Dijkhuis, W. Dierkes. J. Appl. Polym. Sci. 102 (2006), 5948.

14. A. Jalilvand, I Ghasemi, M. Karrabi, H. Azizi. Iran Polym. J. 16 (2007), 327.

15. P. Sutanto, F. Picchioni, L. Janssen. Chem. Eng. Sci. 61 (2006), 7077. 
16. H. Si, T. Chen, Y. Zhang. J. Appl. Polym. Sci. 128 (2013), 2307.

17. B. Suryanarayanam. Chem. Eng. World. 29 (1994), 57.

18. A. Bani, G. Polacco, G. Gallone. J. Appl. Polym. Sci. 120 (2011), 2904.

19. V. Pistor, C. Henrique, P. Olivera, R. Fiorio, A. Zattera. Polym. Eng. \& Sci. 51 (2011), 697.

20. E. Thostenson, T. Chou. Composites. 30 (1999), 1055.

21. V. Pistor, A. Zattera. J. Elas \& Plast. published online (2012).

22. J. Oh, A. Isayev,M. Rogunova. Polymer. 44 (2003), 2337.

23. J. Yun, A. Isayev, Rubber Chem. Technol. 76 (2003),253.

24. J. Kim, J. Park. J. Appl. Polym. Sci. 72 (1999), 1543.

25. K. Bredberg. Prog. Rubb. \& Plast Technol. 17 (2001), 149.

26. K. Jiang, J. Shi, Y. Ge, R. Zou, P. Yao, X. Li, L. Zhang. J. Appl. Polym. Sci. 127 (2013), 2398.

27. M. Verbruggen, L. vander Does, J. Noordermeer, M. Van Duin, H. Manuel. Rubber Chem. Technol. 72 (1999), 731.

28. J. Olmsted, G. William. Chemistry: the molecular science, W. C. Brown (1997), 407.

29. J. Yun, A.I. Isayev. Polym. Eng. Sci. 43 (2003), 809.

30. J.Yun, V. Yashin, A.I. Isayev. J. Appl. Polym. Sci. 91 (2004), 1646.

31. M. Mouri, H. Okamoto, M. Matsushita, H. Honda, K. Nakashima, K. Takeushi, Y. Suzuki, M. Owaki. Int. polym. Sci. Technol. 27 (2000), 23.

32. Van Duin, J. Noordemeer, M. Verbruggen. US Patent 2,003,013,776 (2003).

33. http://www.coperion.com/en/compounding-extrusion/machines-systems/cte-cky-series/ 
34. British standard institution, Physical testing of rubber- Curemeter - BS 903- A60.1 (2000).

35. S. Wolff. Rubber Chem. Technol. 66 (1993), 163.

36. F. P. Baldwin, G. Verstrate. Rubber Chem. Technol. 45 (1972), 709.

37. A. Bani, G. Polacco, G. Gallone. J. Appl. Polym. Sci. 120 (2011), 2904.

38. British standards institution, Method for determination of tensile stress strain properties, BS 903, A2, UK (1995).

39. British standards institution, Physical testing of rubber: Method for determination of hardness, BS 903, A26, London, UK (1995).

40. British Standards Institution, Physical testing of rubber: Method for determination of tear strength trousers, angle and crescent test pieces. British Standard 903: Part A3; London, UK (1995).

41, Kawasaki et al., Ordinary overall research publications meeting of Japanese Rubber Society, lecture reprints, 36 (1979), 37.

42. M. Gradwell, W. McGill. J. Appl. Polym. Sci. 51 (1994), 169.

43. http://www.allsealsinc.com/allseals/Orings/or13.htm

44. K. L. Je, D. H. Chang. Polymer. 41 (2000), 1799.

45. M. A. Kader, A. K. Bhowmick, T. Inoue, T. Chiba. J. Mat. Sci. 37(2002), 1503.

46. K. E. Polmanteer, C. W. Lentz. Rubber Chem. Technol. 48 (1975), 795.

47. S. Tantayanon, S. J. Juikham. J. Appl. Polym. Sci. 91 (2004), 510.

48. G. Tao, Q, He, Y, Xia, G, Jia, H, Yang, W, Ma. J. Appl. Polym. Sci. 129 (2013) 2598.

49. C, Jacob, P. P. DE, A. K. Bhowmick, S. K. DE. J. Appl. Polym. Sci. 82 (2001), 3293. 


\section{FIGURE CAPTIONS}

Scheme 1 - Chemical structural of EPDM rubber with ENB.

Scheme 2 - Chemical structure of 2-mercaptobenzothiazoledisulfide (MBTS).

Scheme 3- Chemical structure of tetramethylthiuram disulfide (TMTD).

Scheme 4 - Proposed devulcanization mechanism by MBTS.

Figure 1 - TGA traces for the EPDM rubber waste powder after oil extraction by acetone.

Figure 2 - The twin screw extruder for applying shearing action during devulcanization.

Figure 3 - Devulcanized waste rubber after extrusions (compound A).

Figure 4 - Compound temperature vs. mixing time for the reference compound and blends containing different amounts of Compound A.

Figure 5 - Compound temperature vs. mixing time for the reference compound and blends containing different amounts of Compound B.

Figure 6 - Mooney viscosities vs. wt\% of Compound A and Compound B in the blends.

Figure 7 - $\Delta$ Torque vs. wt \% of Compound $\mathrm{A}$ in the blend.

Figure 8 - Scorch and optimum cure times vs. wt \% of Compound A in the blend.

Figure 9 - $\Delta$ Torque vs. wt \% of Compound B in the blend.

Figure 10 - Scorch and optimum cure times vs. wt \% of Compound B in the blend.

Figure 11 - Cure rate index vs. wt \% of Compound A and Compound B in the blends.

Figure 12 - Tensile strength vs. wt \% of Compound A and Compound B in the blends.

Figure 13 - Elongation at break vs. wt\% of Compound A and Compound B in the blends.

Figure 14 - Modulus at different elongations vs. wt\% of Compound A in the blend. 
Figure 15 - Modulus at different elongations vs. wt \% of Compound B in the blend.

Figure 16 - Hardness vs. wt\% of Compound A or Compound B in the blends .

Figure 17 - Tear strength vs. wt\% of Compound A and Compound B in the blends.

Figure 18 - Compression set vs. we \% of Compound A or Compound B in the blends.

Figure 19 - SEM micrograph showing the microstructure of the reference compound.

Figure 20 - SEM micrograph showing the microstructure of Compound A.

Figure 21 - SEM micrograph showing the microstructure of compound A-2 containing $20 \mathrm{wt} \%$ of Compound A.

Figure 22 - SEM micrograph showing the microstructure of compound A-3 containing $40 \mathrm{wt} \%$ of Compound A.

Figure 23 - SEM micrograph showing the microstructure of compound A-4 containing $60 \mathrm{wt} \%$ of Compound A. 


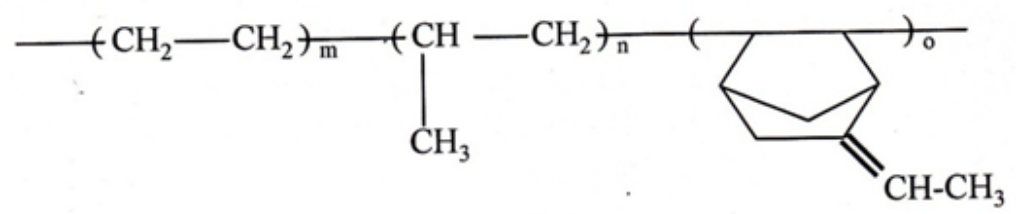

Scheme 1 - Chemical structural of EPDM rubber with ENB.

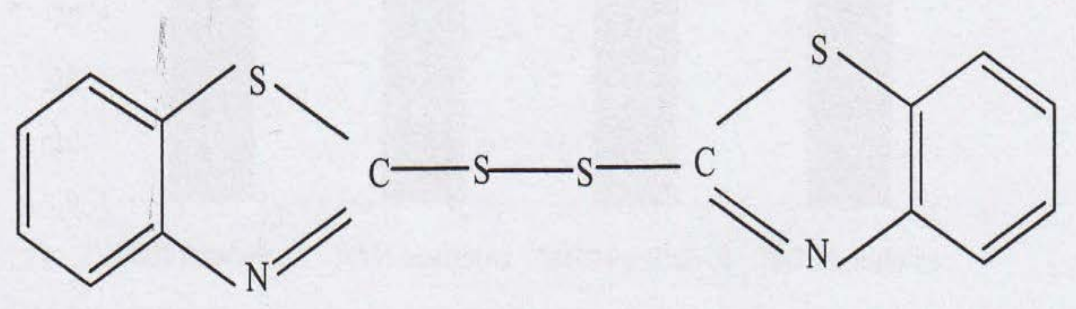

Scheme 2 - Chemical structure of 2-mercaptobenzothiazoledisulfide (MBTS).

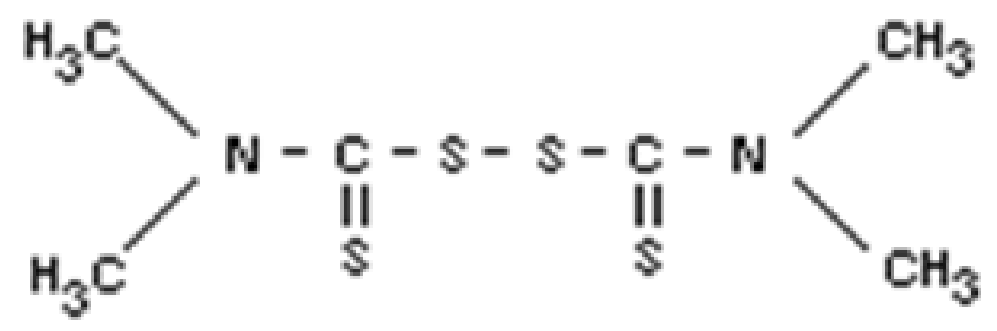

Scheme 3- Chemical structure of tetramethylthiuram disulfide (TMTD). 

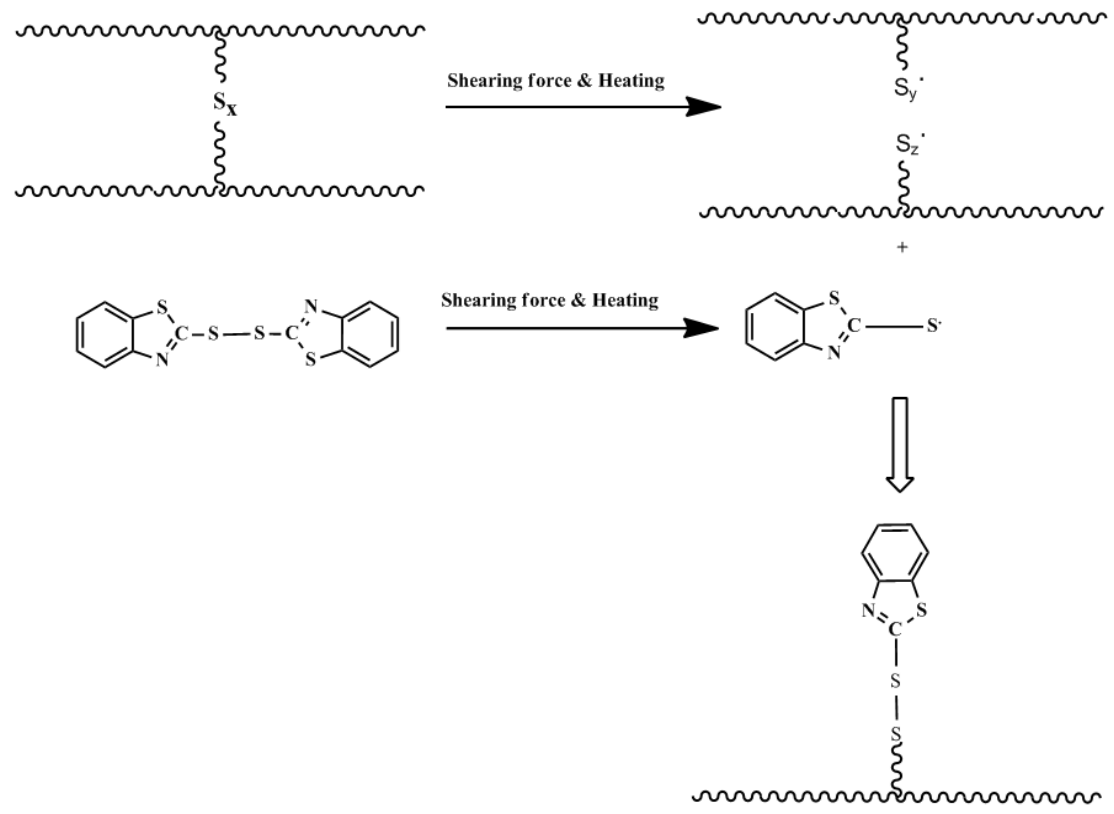

Scheme 4 - Proposed devulcanization mechanism by MBTS.

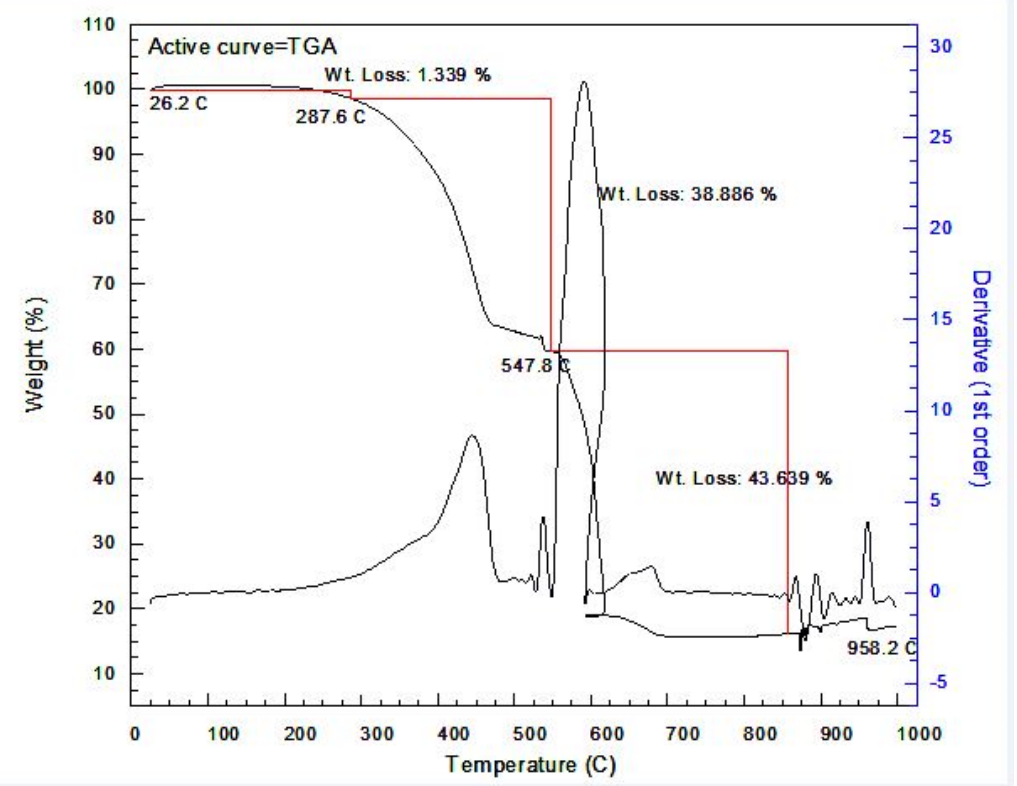

Figure 1 - TGA traces of the EPDM rubber waste powder after oil extraction by acetone. 


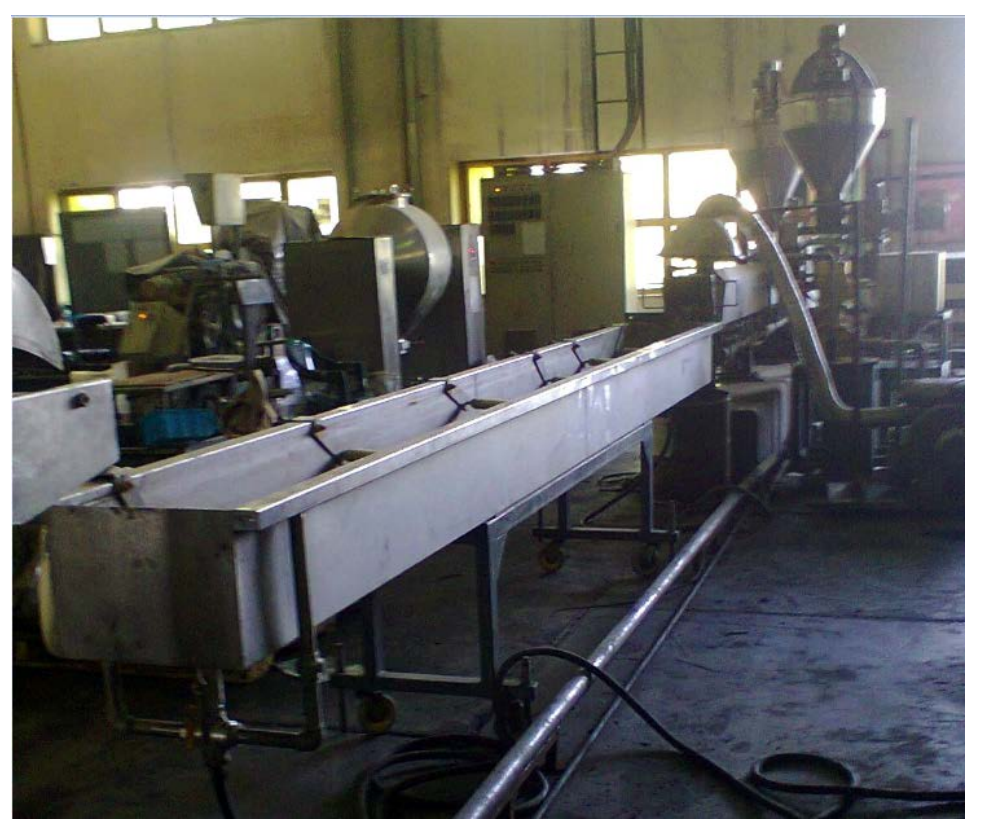

Figure 2 - The twin screw extruder for applying shearing action during devulcanization.

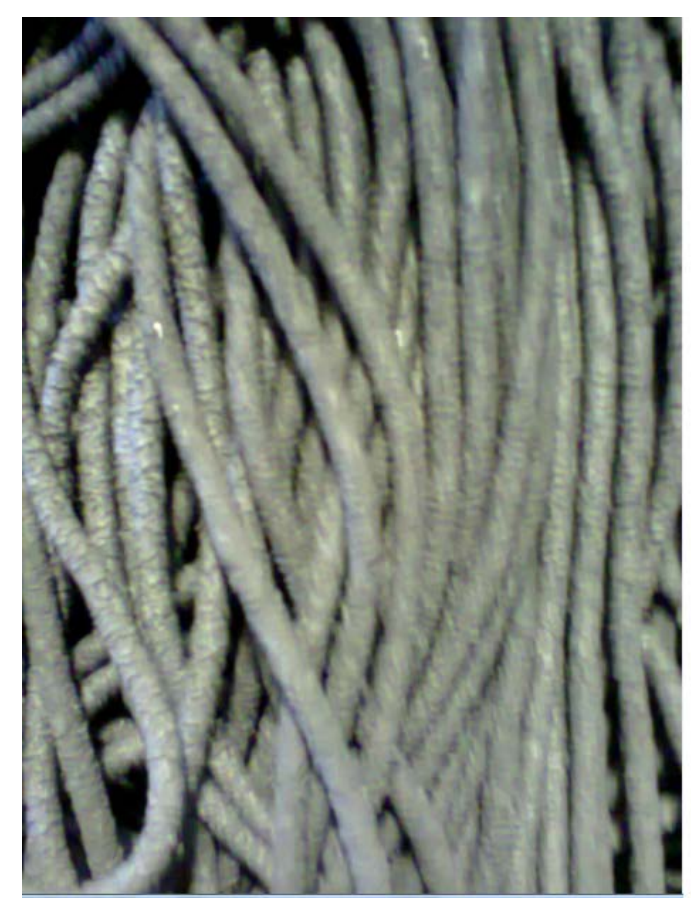

Figure 3 - Devulcanized waste rubber after extrusions (compound A). 


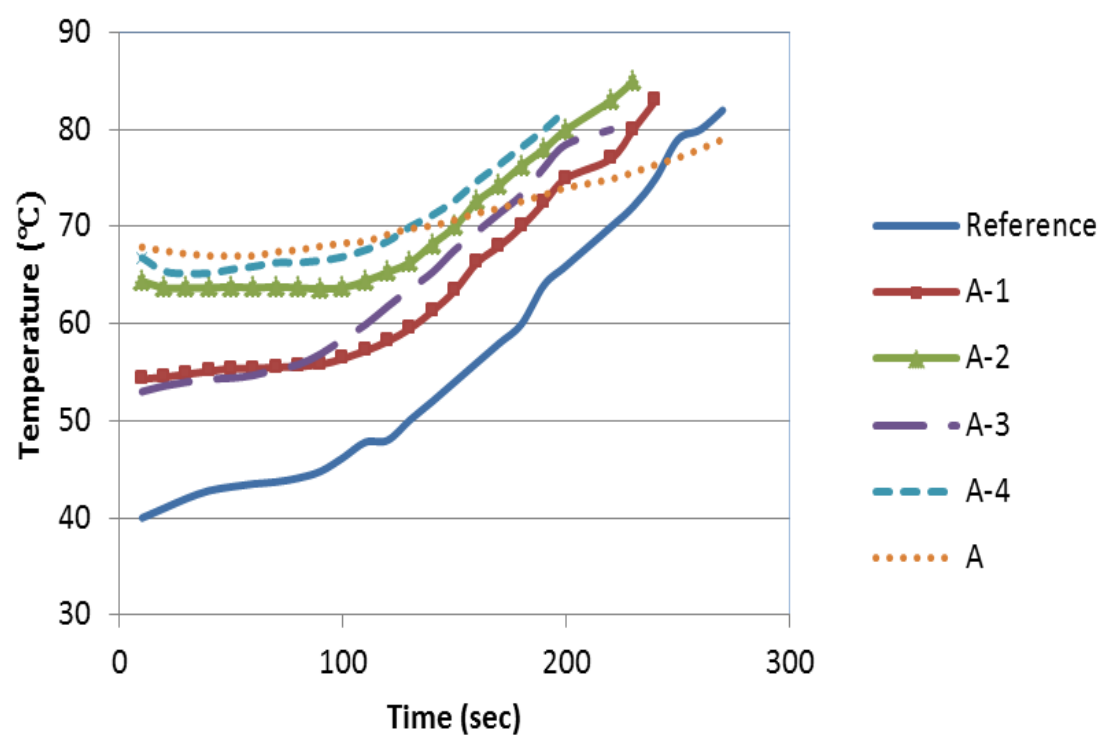

Figure 4 - Compound temperature vs. mixing time for the reference compound and blends containing different amounts of Compound A.

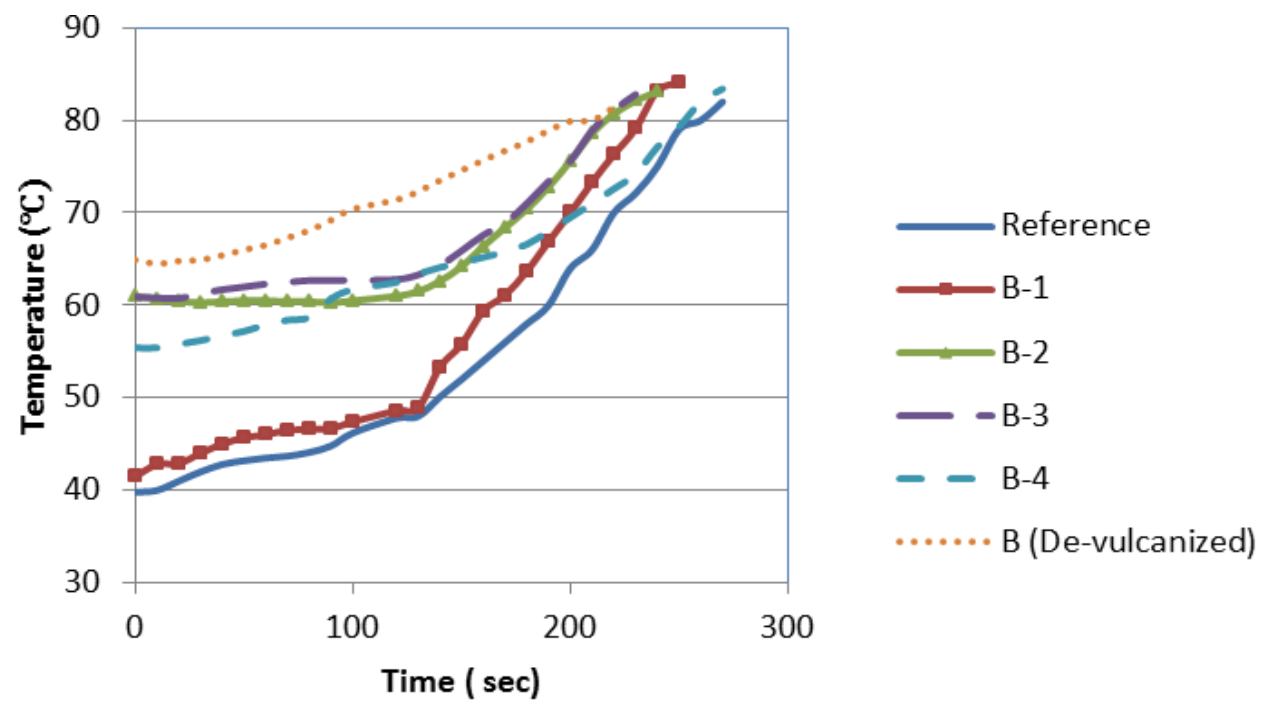

Figure 5 - Compound temperature vs. Mixing time for the reference compound and blends containing different amounts of Compound B. 


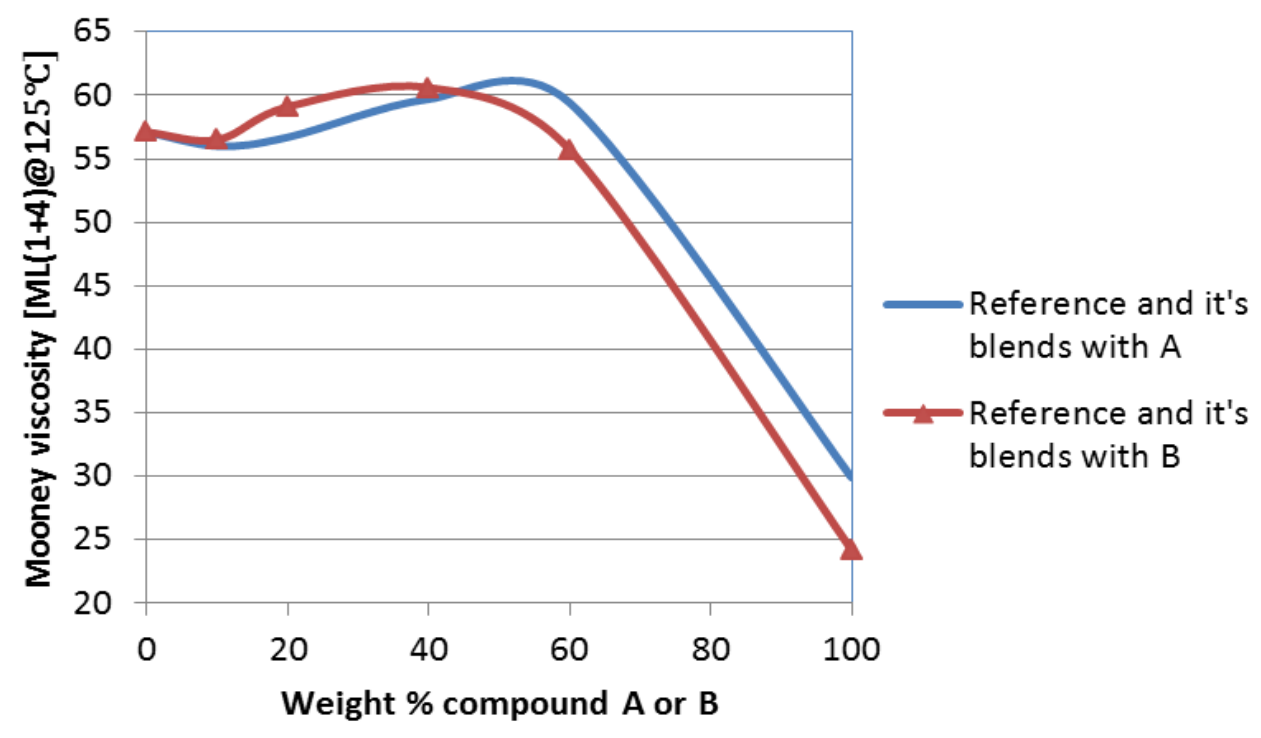

Figure 6 - Mooney viscosities vs. wt\% of Compound A and Compound B in the blends.

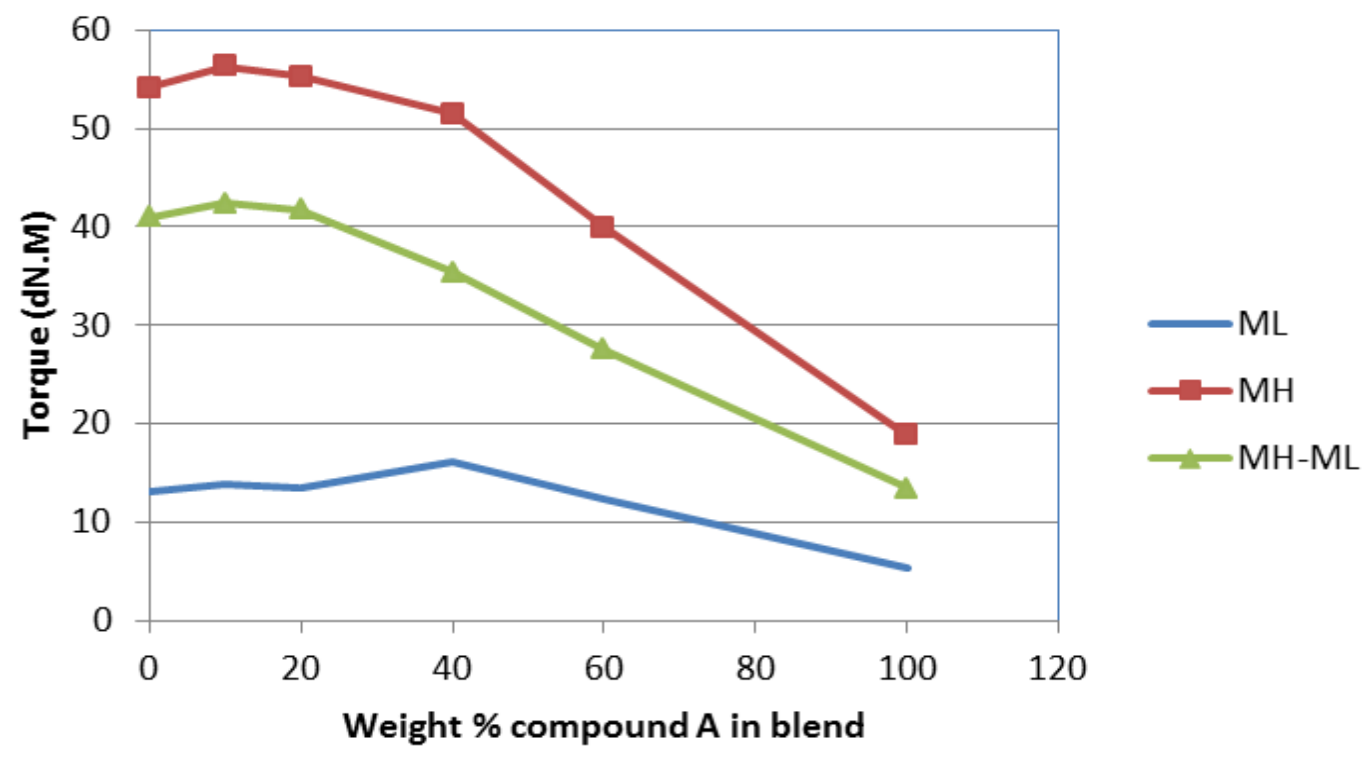

Figure 7 - $\Delta$ Torque vs. wt \% of Compound $\mathrm{A}$ in the blend. 


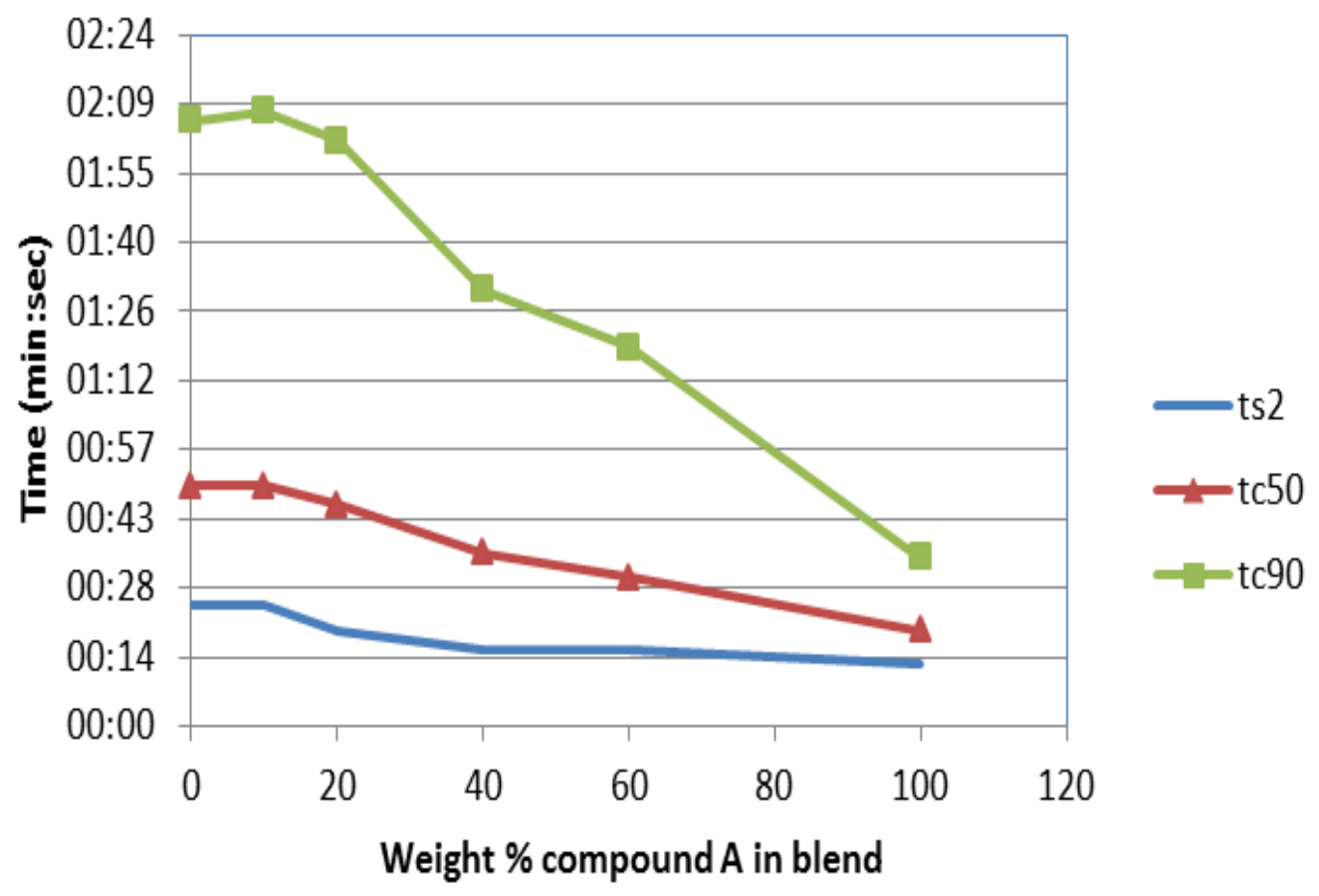

Figure 8 - Scorch and optimum cure times vs. wt \% of Compound A in the blend.

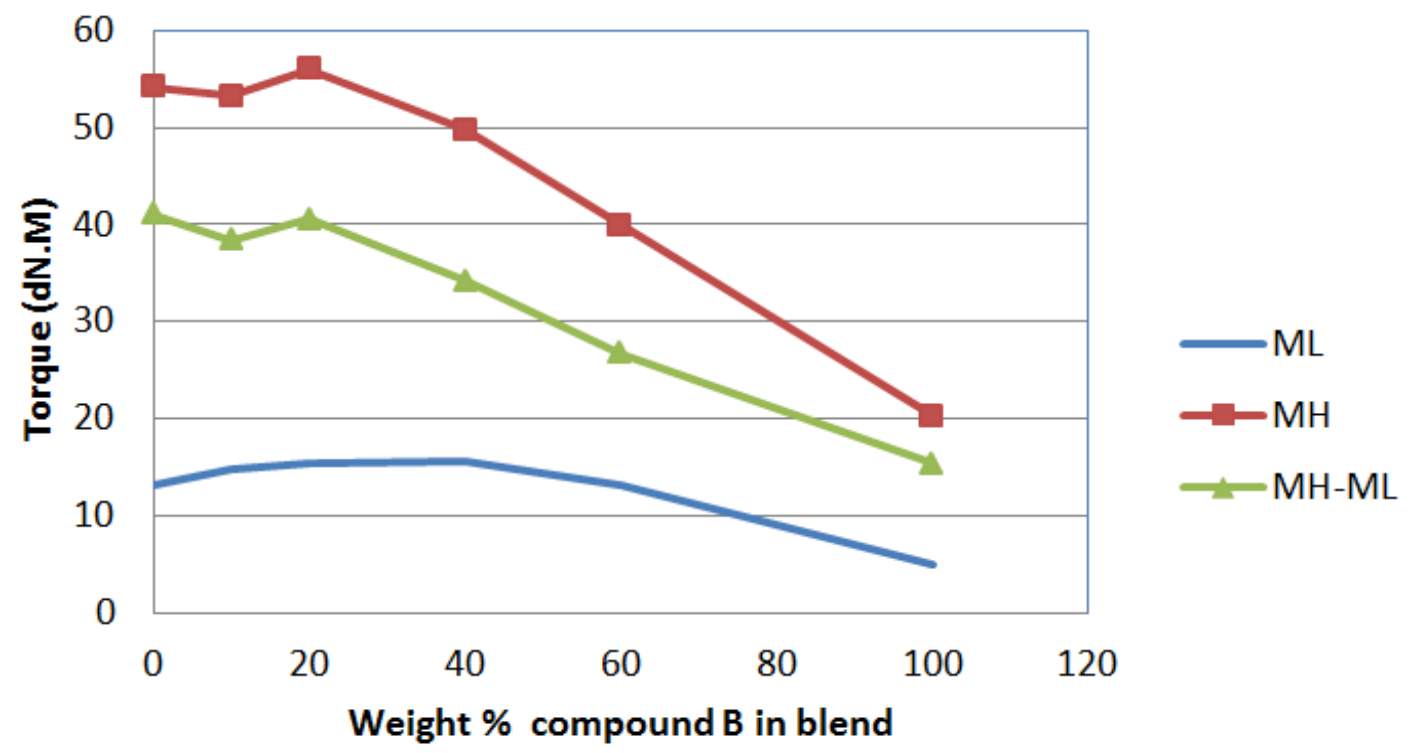

Figure 9 - $\Delta$ Torque vs. wt \% of Compound B in the blend. 


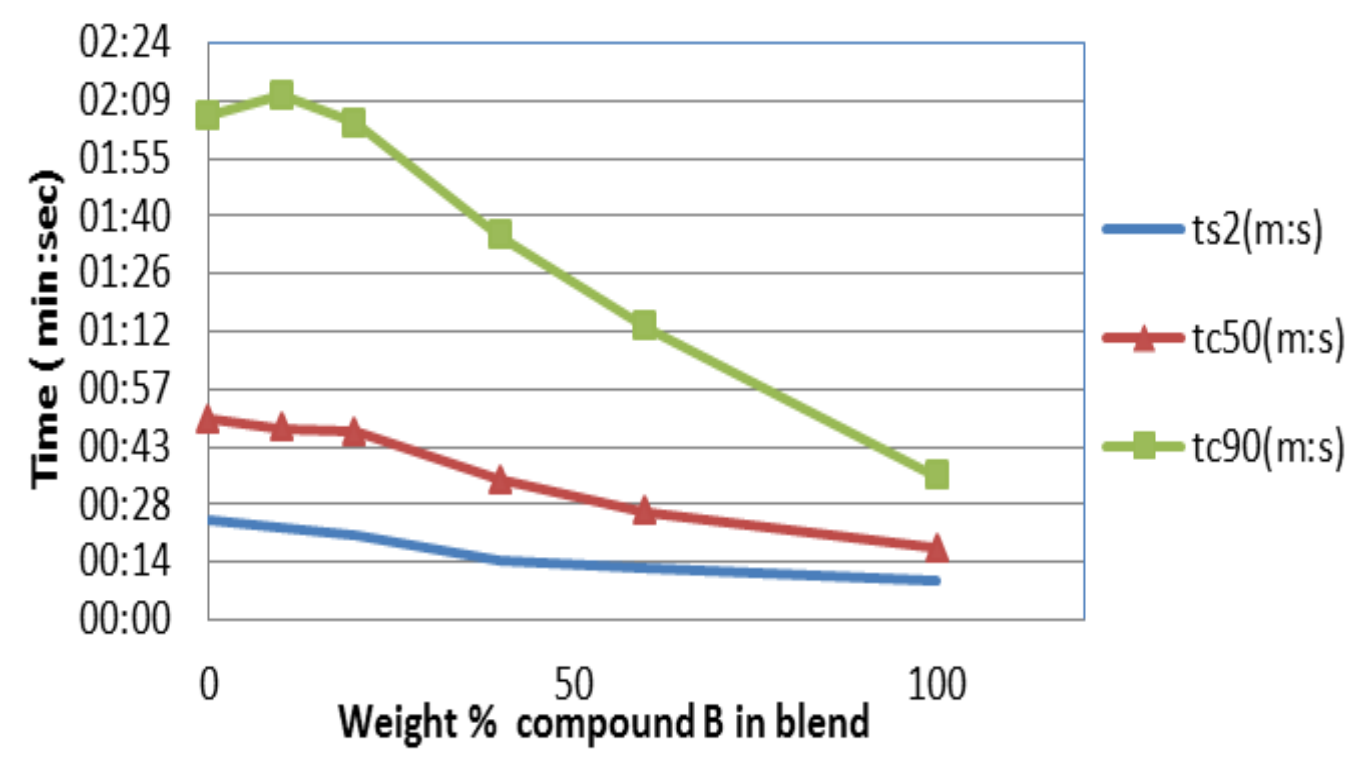

Figure 10 - Scorch and optimum cure times vs. wt \% of Compound B in the blend.

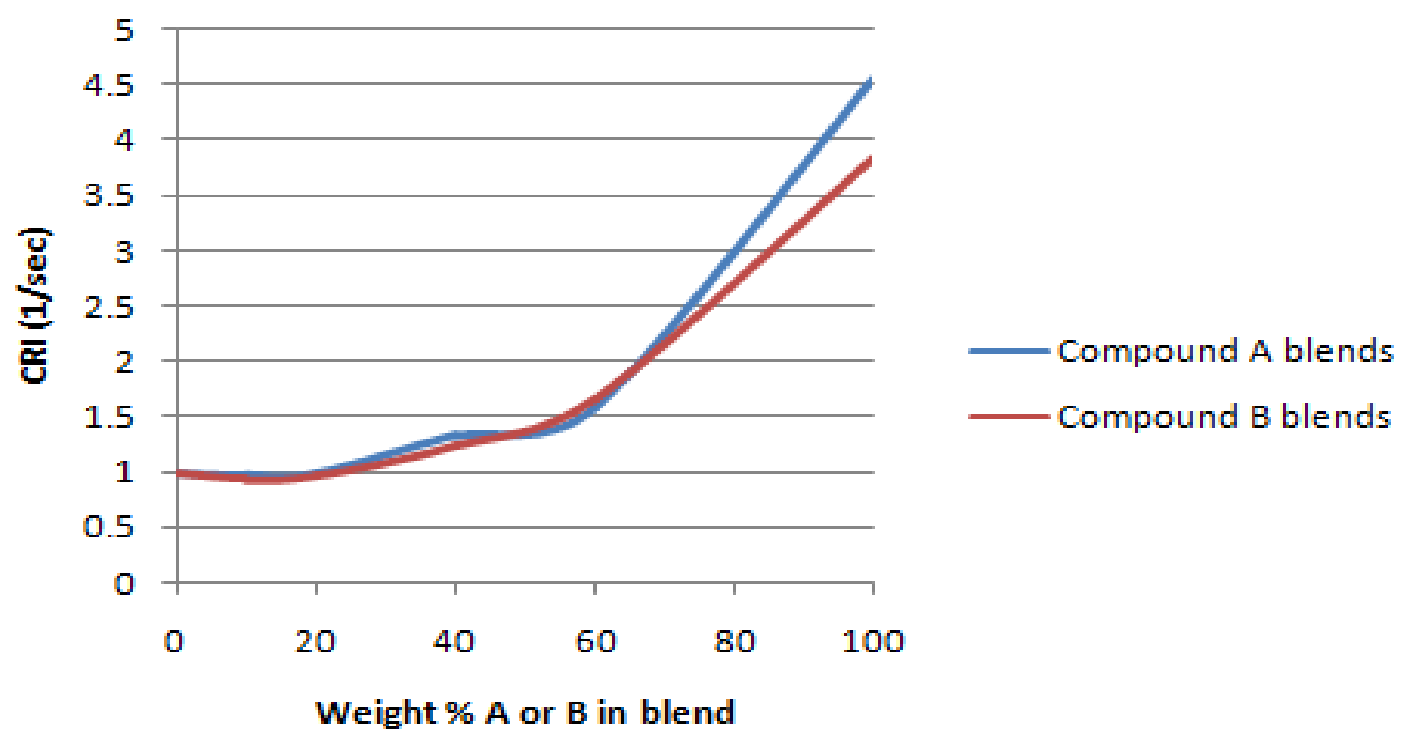

Figure 11 - Cure rate index vs. wt \% of Compound A and Compound B in the blends. 


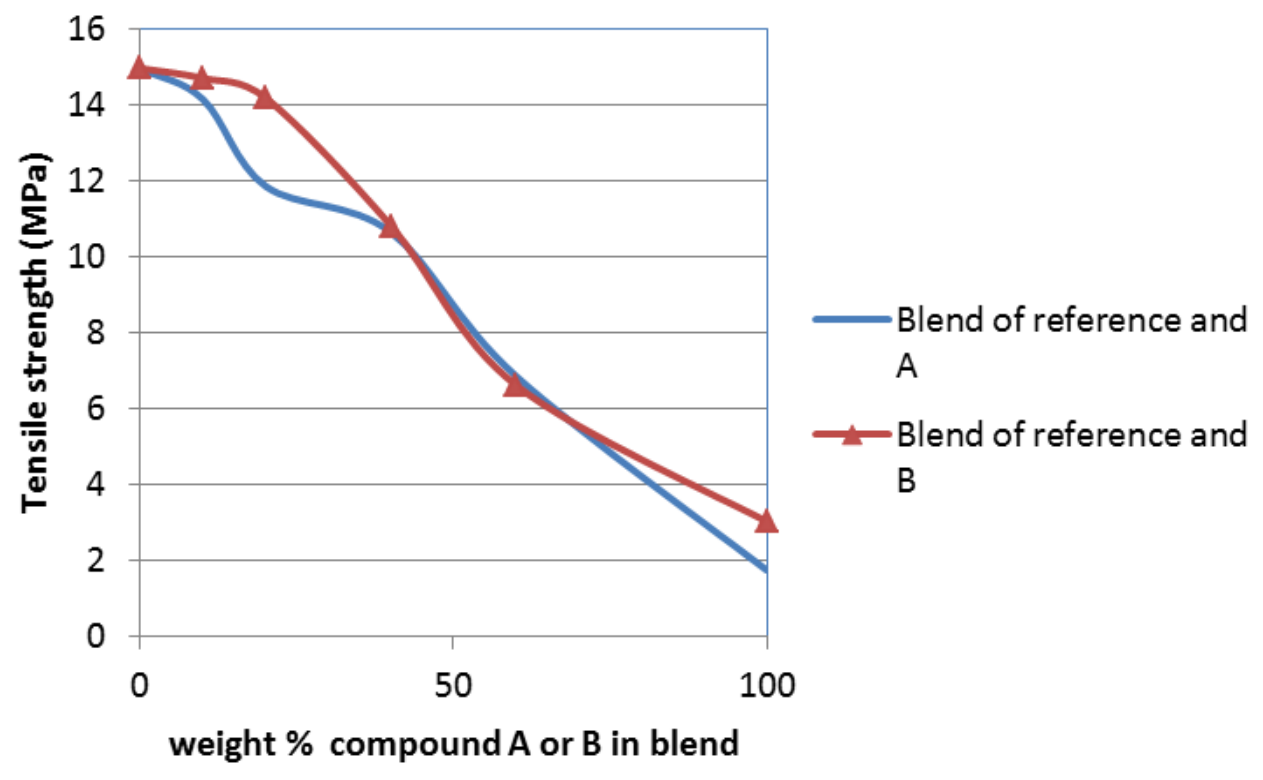

Figure 12 - Tensile strength vs. wt \% of Compound A and Compound B in the blends.

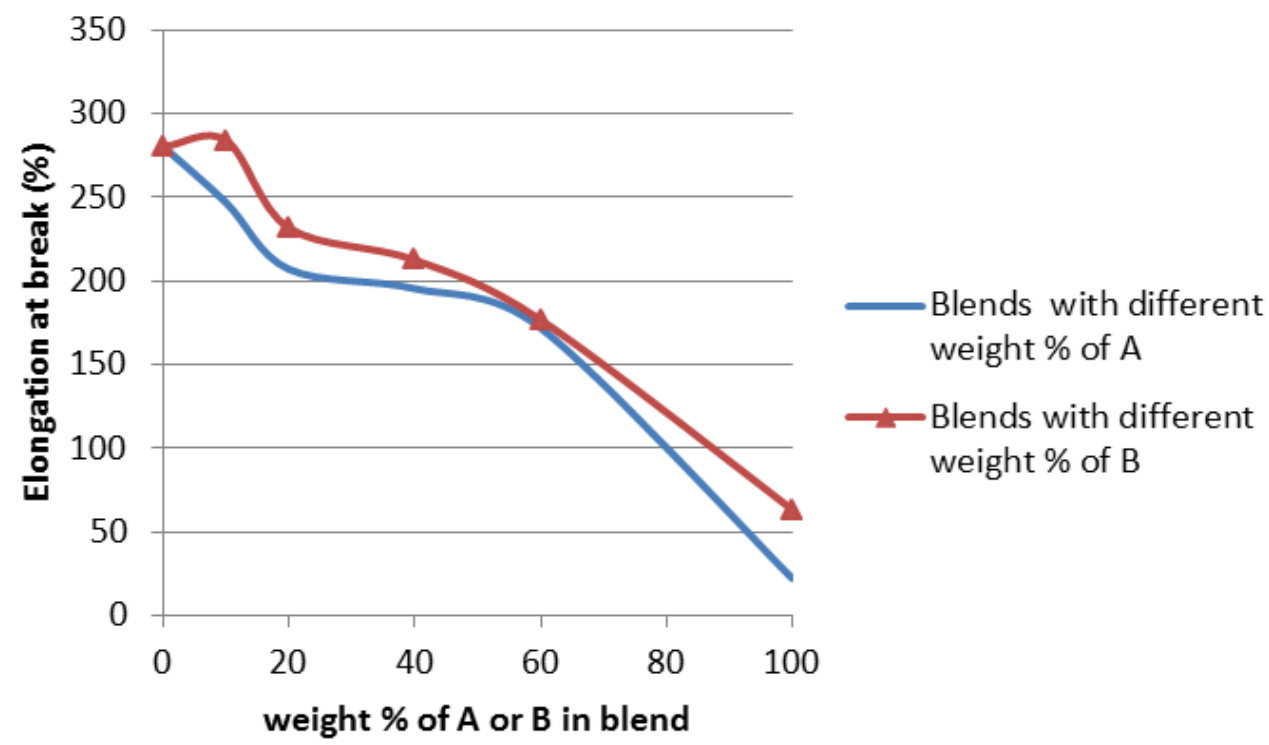

Figure 13 - Elongation at break vs. wt\% of Compound A and Compound B in the blends. 


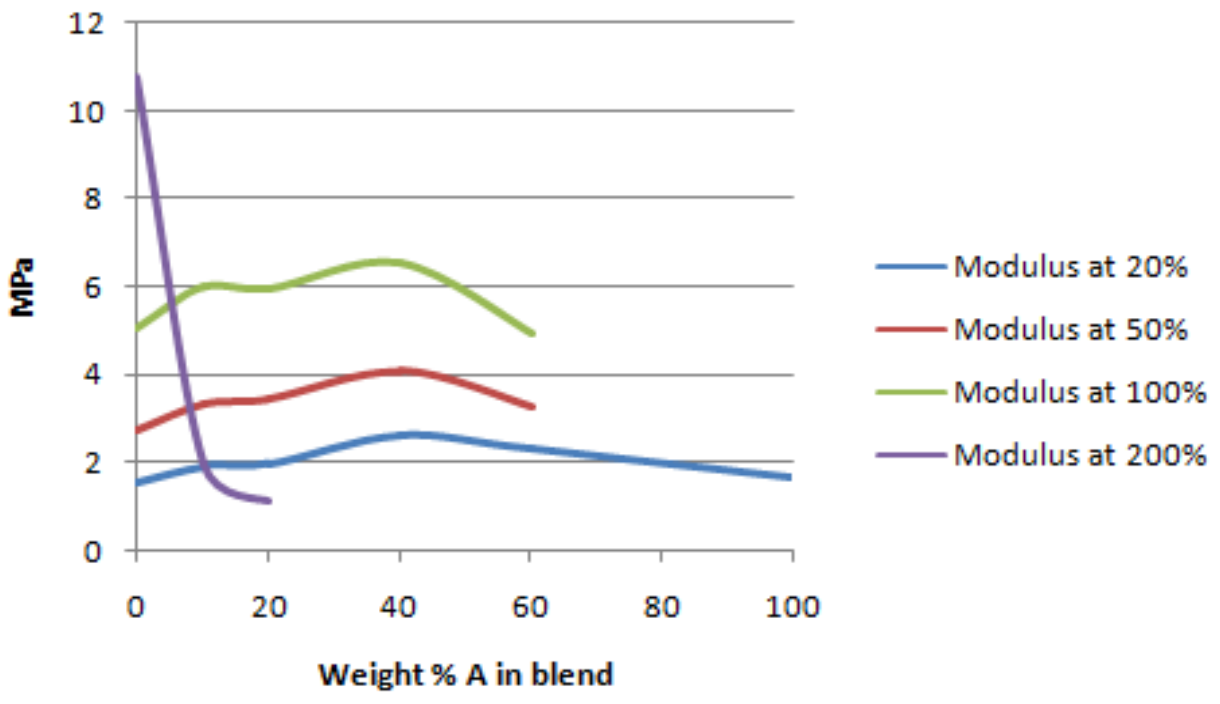

Figure 14 - Modulus at different elongations vs. wt\% of Compound A in the blend.

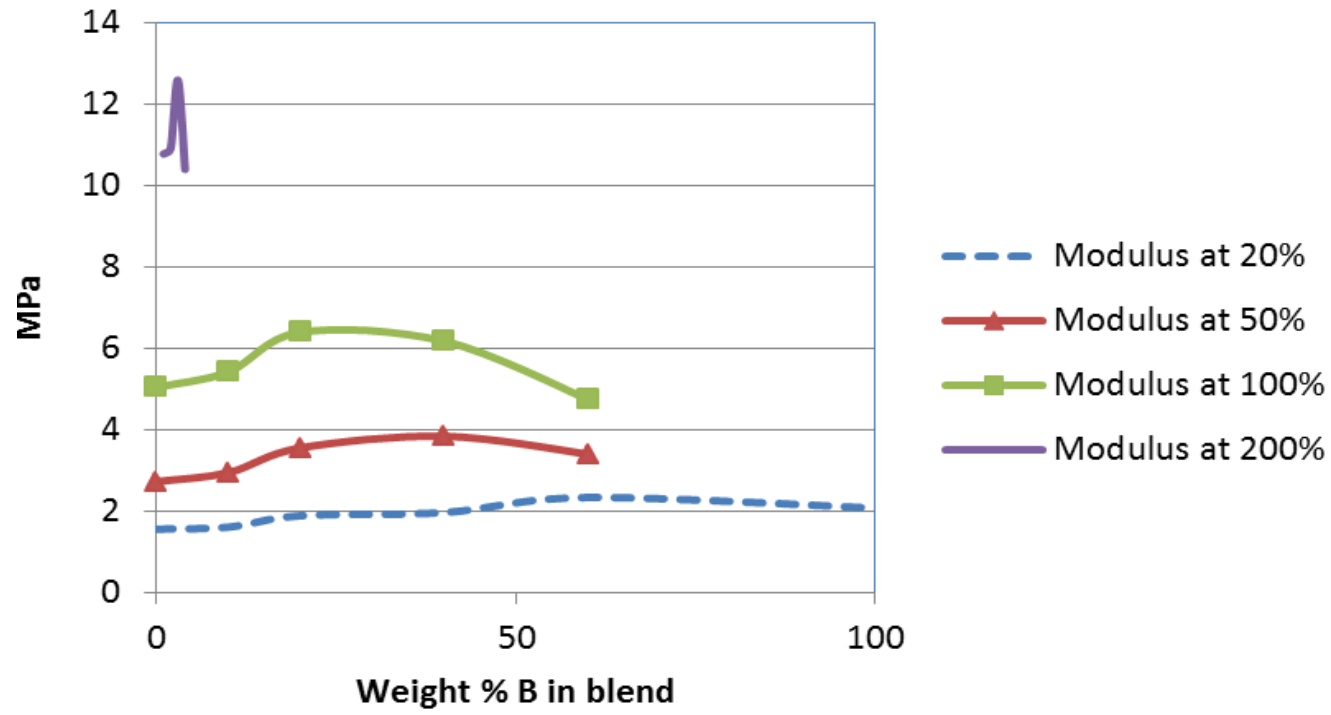

Figure 15 - Modulus at different elongations vs. wt \% of Compound B in the blend. 


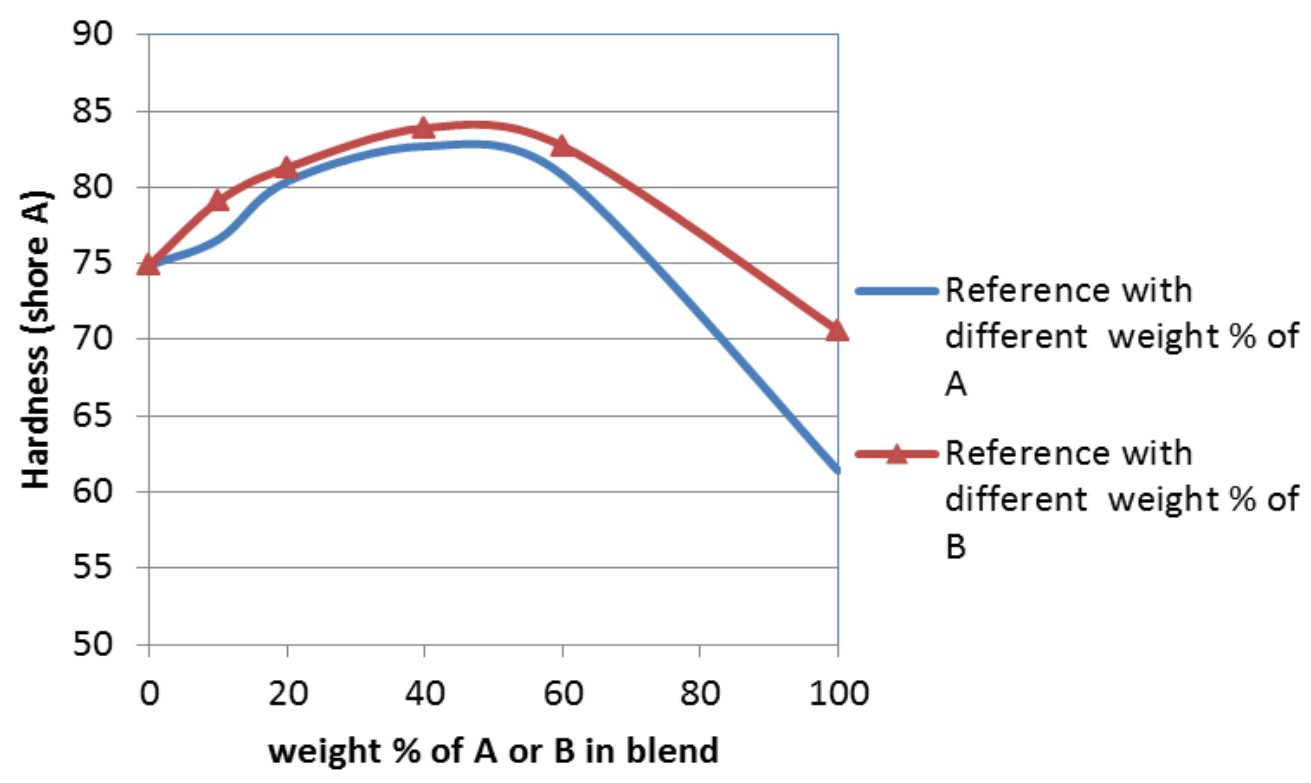

Figure 16 - Hardness vs. wt\% of Compound A or Compound B in the blends.

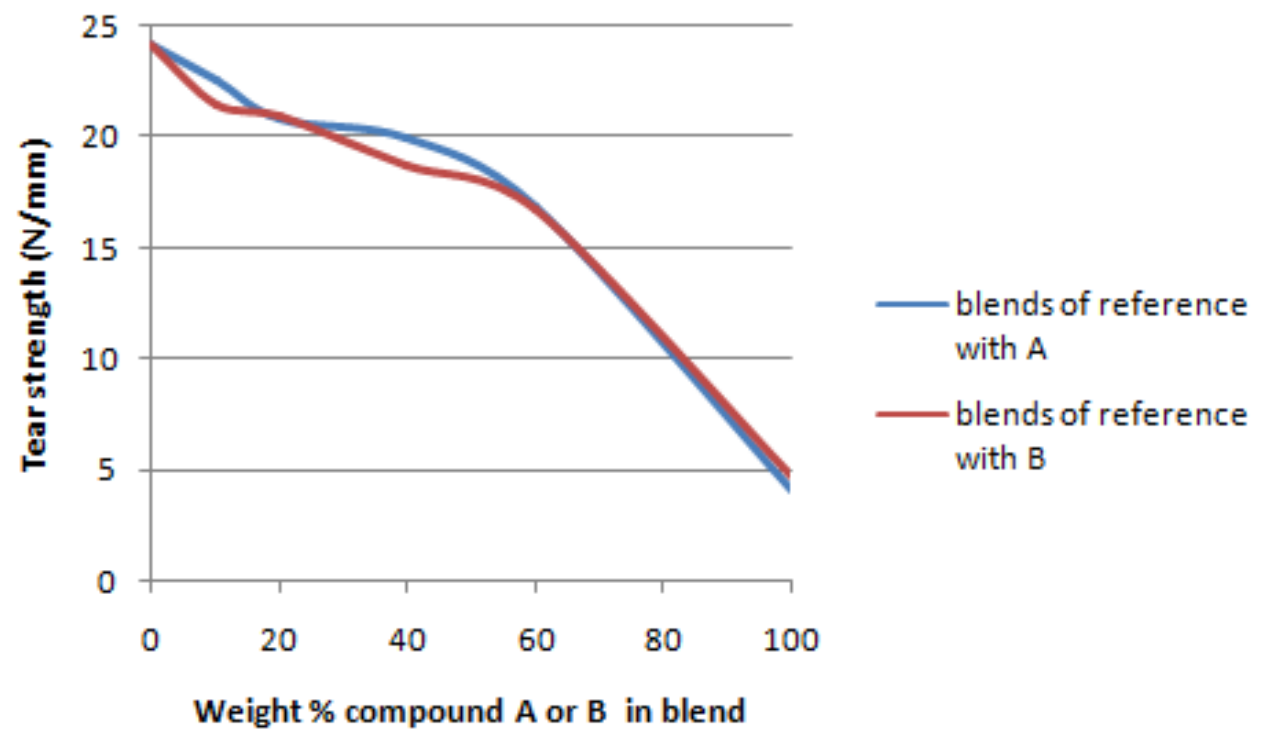

Figure 17 - Tear strength vs. wt\% of Compound A and Compound B in the blends. 


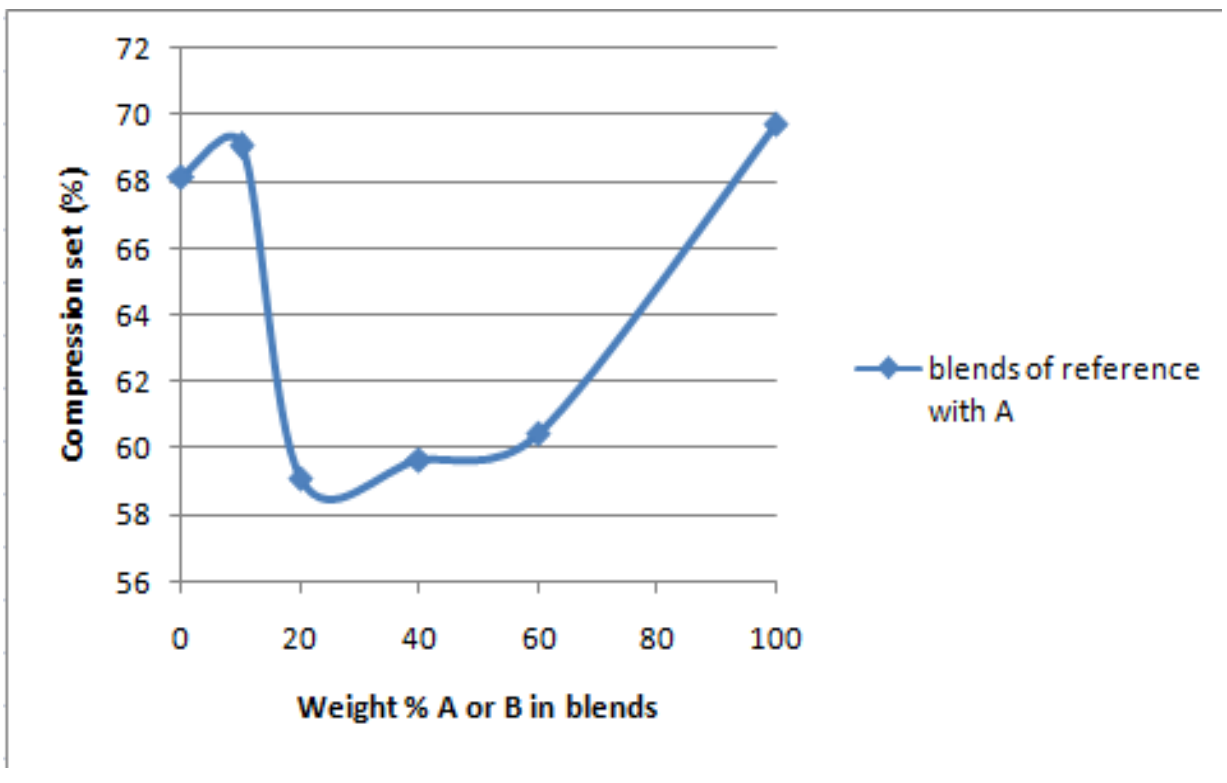

Figure 18 - Compression set vs. we \% of Compound A or Compound B in the blends.

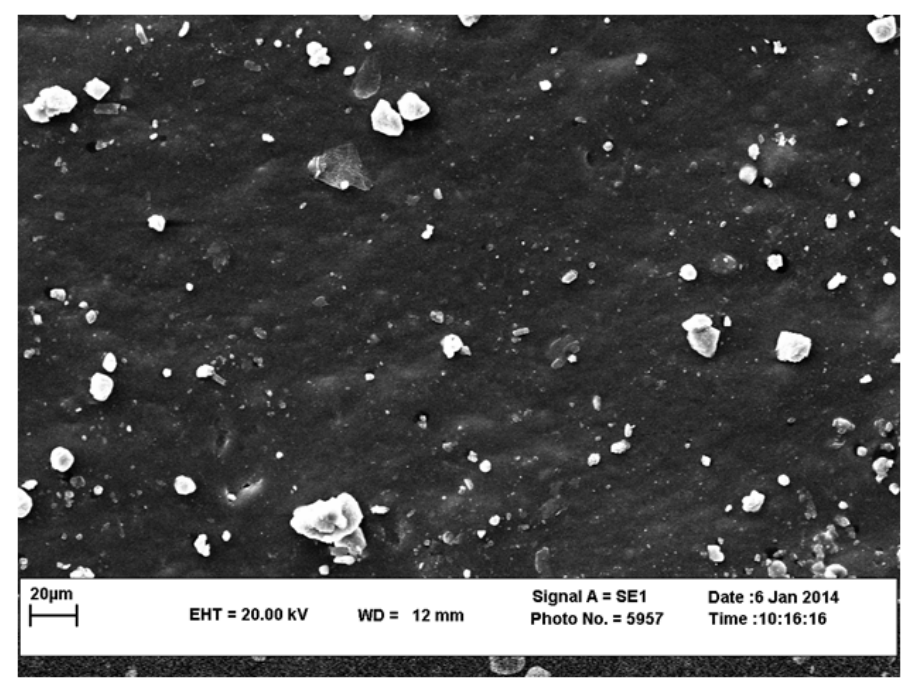

Figure 19 - SEM micrograph showing the microstructure of the reference compound. 


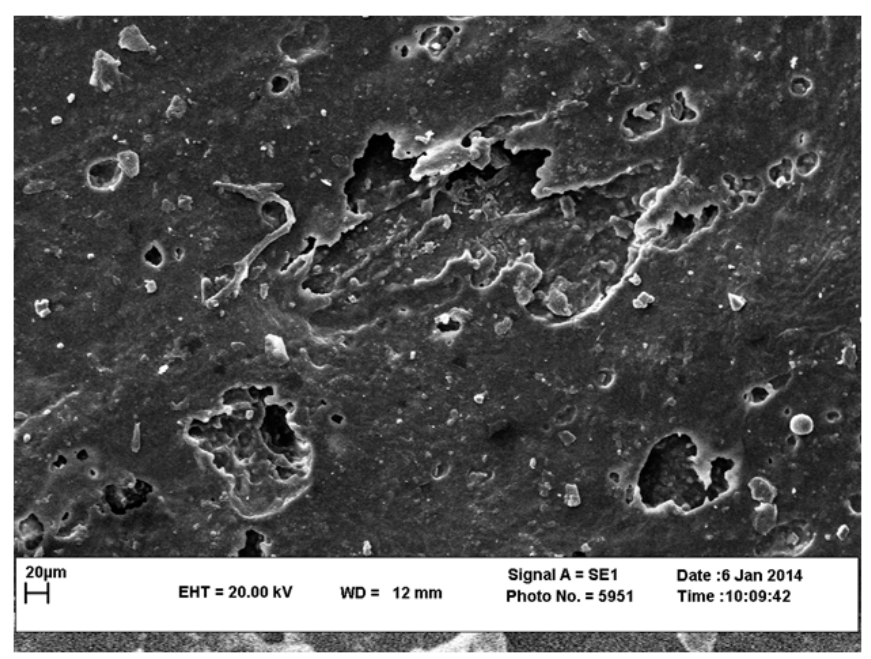

Figure 20 - SEM micrograph showing the microstructure of Compound A.

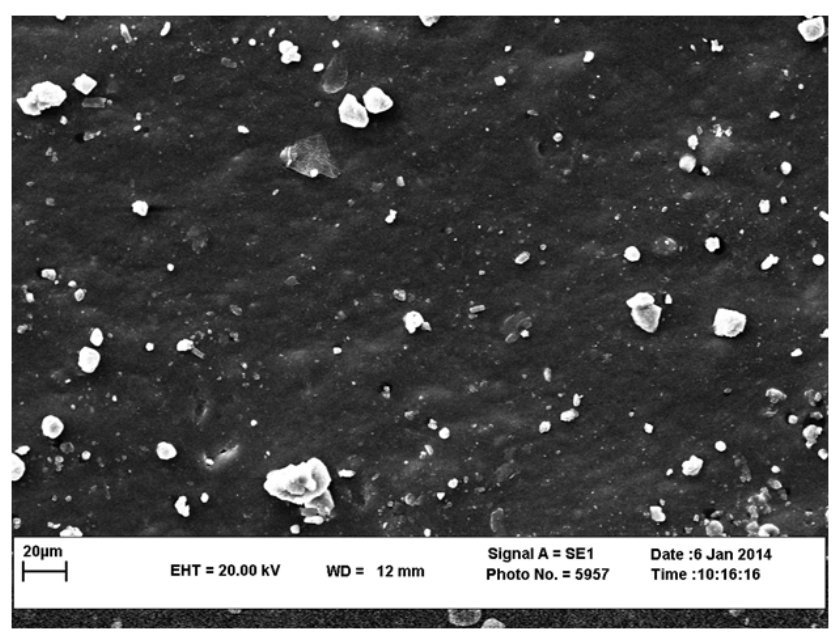

Figure 21 - SEM micrograph showing the microstructure of compound A-2 containing 20 wt $\%$ of Compound A. 


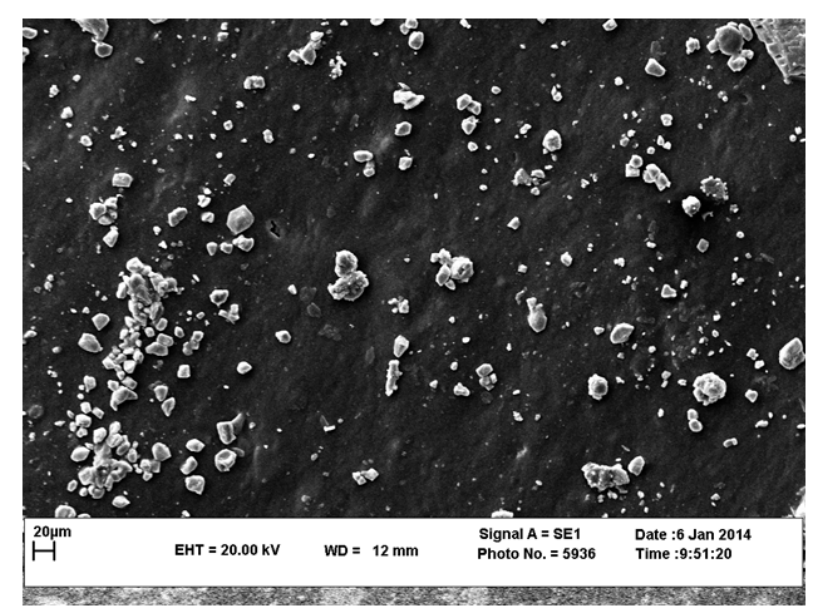

Figure 22 - SEM micrograph showing the microstructure of compound A-3 containing 40 wt $\%$ of Compound A.

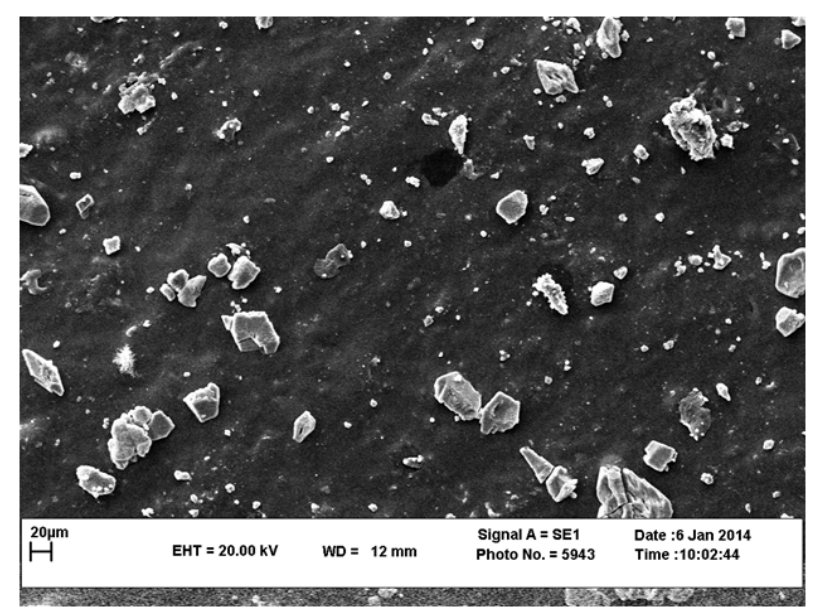

Figure 23 - SEM micrograph showing the microstructure of compound A-4 containing 60 wt \% of Compound A. 
Table 1. Physical properties and composition of EPDM waste powder after oil extraction by acetone

\begin{tabular}{|c|c|c|}
\hline \multicolumn{2}{|l|}{ Property } & Amount \\
\hline \multicolumn{2}{|c|}{ Sol content (\%) } & 0.5 \\
\hline \multicolumn{2}{|c|}{ Density $\left(\mathrm{gr} / \mathrm{cm}^{3}\right)$} & 1.4072 \\
\hline \multicolumn{2}{|c|}{ Crosslink Density $\left(\mathrm{mol} / \mathrm{m}^{3}\right)$} & 186 \\
\hline \multirow{4}{*}{$\vec{D}$} & Others (\%) & 15.45 \\
\hline & Carbon black (\%) & 43.60 \\
\hline & EPDM (\%) & 38.88 \\
\hline & Left oil & 2.07 \\
\hline
\end{tabular}

Table 2. Recipe of the chemical and oils used in the devulcanization process in the extruder

\begin{tabular}{|l|c}
\hline Material & Content \\
\hline EPDM waste rubber powder & $100 \mathrm{Phr}$ \\
\hline MBTS ( reclaiming agent) & $6 \mathrm{Phr}$ \\
\hline Aromatic oil & $5 \mathrm{Phr}$ \\
\hline Paraffinic oil & $10 \mathrm{Phr}$ \\
\hline
\end{tabular}

Table 3. Rotors speeds and temperature during the devulcanization process of the waste powder in the extruder

\begin{tabular}{|l|c|c|c}
\hline $\begin{array}{l}\text { Devulcanized } \\
\text { compound }\end{array}$ & $\begin{array}{c}\text { Main Screw speed } \\
(\mathrm{rpm})\end{array}$ & $\begin{array}{c}\text { Temperature } \\
\left({ }^{\circ} \mathrm{C}\right)\end{array}$ & $\begin{array}{c}\text { Feed screw } \\
\text { speed } \\
(\mathrm{rpm})\end{array}$ \\
\hline $\mathrm{A}$ & 180 & 220 & 6 \\
\hline $\mathrm{B}$ & 220 & 220 & 8 \\
\hline
\end{tabular}

Table 4. Devulcanization and sol percentages, densities and crosslink densities of the devulcanized compounds $\mathrm{A}$ and $\mathrm{B}$

\begin{tabular}{|l|c|c}
\hline Property & Compound B & Compound A \\
\hline Density $\left(\mathrm{g} / \mathrm{cm}^{3}\right)$ & 1.536 & 1.373 \\
\hline Sol content percentage (\%) & 13.1 & 17.6 \\
\hline Crosslink density $\left(\mathrm{mol} / \mathrm{m}^{3}\right)$ & 15.16 & 14.50 \\
\hline Devulcanization percentage (\%) & 91.85 & 92.19 \\
\hline
\end{tabular}


Table 5. Formulations of the reference compound and blends with different amounts of Compound A

\begin{tabular}{|c|c|c|c|c|c|c|c|c|c|c|}
\hline \multirow[t]{2}{*}{ Material } & \multirow[t]{2}{*}{ Reference compound } & \multicolumn{2}{|c|}{ A-1 } & \multicolumn{2}{|c|}{ A-2 } & \multicolumn{2}{|c|}{$\mathrm{A}-3$} & \multicolumn{2}{|c|}{ A-4 } & \multirow[t]{2}{*}{ Compound A } \\
\hline & & Ref. & A & Ref. & A & Ref & A & Ref. & A & \\
\hline EPDM & 100 & 990 & 10 & $\overline{80}$ & 20 & 60 & 40 & 40 & 60 & - \\
\hline N330 & 112 & 101 & 0 & 90 & 0 & 67 & 0 & 45 & 0 & - \\
\hline Oil & 40 & 36 & 0 & 32 & 0 & 24 & 0 & 16 & 0 & - \\
\hline sulfur & 2.5 & 2.25 & $0.07^{-}$ & 2 & 0.14 & 1.5 & 0.28 & 1 & 0.42 & 0.7 \\
\hline $\mathrm{ZnO}$ & 5 & 4.5 & 0.14 & 4 & 0.28 & 3 & 0.56 & 2 & 0.84 & 1.4 \\
\hline Stearic acid & 1 & 0.9 & 0.03 & 0.8 & 0.06 & 0.6 & 0.12 & 0.4 & 0.18 & 0.3 \\
\hline MBTS & 0.5 & 0.45 & 0.01 & 0.4 & 0.03 & 0.3 & 0.06 & 0.2 & 0.09 & 0.15 \\
\hline ZDBC & 1.8 & 1.6 & 0.05 & 1.4 & 0.10 & 1.0 & 0.21 & 0.7 & 0.324 & 0.54 \\
\hline TMTD & 0.7 & 0.63 & 0.02 & 0.5 & 0.04 & 0.4 & 0.08 & 0.2 & 0.126 & 0.2 \\
\hline
\end{tabular}

* All amounts in phr. or $g$

** Typical calculation: $0.3888 \times 82.58 \times 0.9219 \times 0.1 \times 0.025=0.07$

Table 6. Formulations of the reference compound and blends with different amounts of Compound B

\begin{tabular}{|c|c|c|c|c|c|c|c|c|c|c|}
\hline \multirow[t]{2}{*}{ Material } & \multirow{2}{*}{$\begin{array}{l}\text { Reference } \\
\text { compound }\end{array}$} & \multicolumn{2}{|c|}{ B-1 } & \multicolumn{2}{|c|}{ B-2 } & \multicolumn{2}{|c|}{ B-3 } & \multicolumn{2}{|c|}{ B-4 } & Compound B \\
\hline & & Ref. & B & Ref & B & Ref & B & Ref & B & \\
\hline EPDM & 100 & 90 & 10 & 80 & 20 & 60 & 40 & 40 & 60 & - \\
\hline N330 & 112 & 101 & 0 & 90 & 0 & 67 & 0 & 45 & 0 & - \\
\hline Oil & 40 & 36 & 0 & 32 & 0 & 24 & 0 & 16 & 0 & - \\
\hline sulfur & 2.5 & 2.25 & $0.07-$ & 2 & 0.14 & 1.5 & 0.28 & 1 & 0.42 & 0.7 \\
\hline $\mathrm{ZnO}$ & 5 & 4.5 & 0.14 & 4 & 0.28 & 3 & 0.56 & 2 & 0.84 & 1.4 \\
\hline Stearic acid & 1 & 0.9 & 0.03 & 0.8 & 0.06 & 0.6 & 0.12 & 0.4 & 0.18 & 0.3 \\
\hline MBTS & 0.5 & 0.45 & 0.015 & 0.4 & 0.03 & 0.3 & 0.06 & 0.2 & 0.09 & 0.15 \\
\hline ZDBC & 1.8 & 1.6 & 0.054 & 1.4 & 0.108 & 1.08 & 0.216 & 0.7 & 0.32 & 0.54 \\
\hline TMTD & 0.7 & 0.63 & 0.02 & 0.5 & 0.04 & 0.42 & 0.08 & 0.2 & 0.12 & 0.2 \\
\hline
\end{tabular}

* All amounts in phr. or $g$

** Typical calculation: $0.3888 \times 82.58 \times 0.9185 \times 0.1 \times 0.025=0.07$ 